\title{
Gas Test Loop Technical and Functional Requirements
}

Glen R. Longhurst Soli T. Khericha James $L$. Jones

September 2004

Idaho National Engineering and Environmental Laboratory Bechtel BWXT Idaho, LLC 

INEEL/EXT-04-02273

\title{
Gas Test Loop Technical and Functional Requirements
}

\author{
Glen R. Longhurst \\ Soli T. Khericha \\ James L. Jones
}

September 2004

\section{Idaho National Engineering and Environmental Laboratory Fission and Fusion Systems Department \\ Idaho Falls, Idaho 83415}

Prepared for the

U.S. Department of Energy

Assistant Secretary for Nuclear Energy

Under DOE Idaho Operations Office

Contract DE-AC07-99ID13727 


\begin{abstract}
This document defines the technical and functional requirements for a gas test loop (GTL) to be designed and constructed to provide a high intensity fastflux irradiation environment for developers of advanced-concept nuclear reactors. This capability is needed to meet fuels and materials testing requirements of Generation IV (GEN IV) reactors, the Advanced Fuel Cycle Initiative (AFCI) and other programs such as the Space Nuclear Power development program. The overall GTL technical objective is to provide developers with the means for investigating and qualifying fuels and materials needed for advanced reactor concepts. The testing environment includes a fastflux neutron spectrum of sufficient intensity to perform accelerated irradiation testing. Appropriate irradiation temperature, gaseous environment, test volume, diagnostics, and access and handling features are also needed. This document serves to identify those requirements as well as generic requirements applicable to any system of this kind.
\end{abstract}





\section{EXECUTIVE SUMMARY}

This document has the purpose of identifying functional and operational requirements for a system that can simulate the fast-flux operating environment for advanced fission reactors.

As developers of advanced nuclear reactor concepts prepare to design and build prototypes, it is essential that there be an adequate information base on the behavior in their intended service environments of fuels and materials to be used in those reactors. The Advanced Fuel Cycle Initiative (AFCI) and Generation IV Reactor Program (GEN IV) will be exploring reactor concepts, many of which are fast-flux gas-cooled reactors, and related fuels and materials technologies. Other concepts are for thermal reactors but with advanced fuels and cooling options. A preliminary investigation suggests there is currently no available test facility that can replicate the test environments needed to qualify fuels and materials for those reactors. Other initiatives, such as the NASA program to provide nuclear reactor power for space exploration and planetary surface applications have similar needs for testing in fast-flux environments.

The Gas Test Loop (GTL) Project has been initiated to develop test assemblies that can be used in an existing irradiation facility to provide the test environments needed by these programs. The range of parameters called for by the various programs that may make use of the GTL suggests the greatest economy will be achieved by having two implementations of the GTL concept, each adapted to a different kind of testing. Before any such assemblies can be designed or constructed, it is essential to define the technical and functional requirements they must meet. This document provides those technical and functional requirements.

The various reactor programs will have differing needs for environmental parameters. Indeed, the testing for most programs will involve two distinctly different kinds of testing. One addresses the damage and property changes inflicted on fuels and materials by the neutron (and to a less extent gamma) fields under their intended operating conditions. For such tests, neutron flux and energy spectra are highly important. Other tests will be more concerned with the evolution of fission fragments and activation products from fuels and materials and the transport of those materials through the coolant system. There, heating power will be more important than neutron energy. There, too, meaningful representation of the coolant loop with its flows and thermal conditions will be essential.

Table 2 lists the required features the GTL must have to meet the stated objectives of the developmental reactor programs mentioned. It is important to note that the values shown there are in many cases extremes and that not all requirements will be imposed on each implementation of the GTL system. Testing requirements for the individual programs supported will dictate the specific parameters that must be met in support of that program. The required features listed, where applicable, are considered the minimum acceptable for the GTL. Also listed are desirable features, which will make the GTL more serviceable to users but incorporation of these features will be determined by cost effectiveness and technical feasibility. 
Table 1. Summary of features required by the Gas Test Loop. Values in parentheses refer specifically to test implementations where evolution and transport of fission fragments and activation products are the main concerns. Not every requirement will apply to each implementation.

\begin{tabular}{|c|c|c|c|}
\hline Parameter & Required & Desired & Comments \\
\hline Test volume length (cm) & 15.5 & 61 & \\
\hline Test volume diameter $(\mathrm{cm})$ & 2.54 & 6.0 & \\
\hline $\begin{array}{l}\text { Fast flux intensity }\left(\mathrm{n} / \mathrm{cm}^{2} . \mathrm{s} \text {, }\right. \\
\mathrm{E}>0.1 \mathrm{MeV} \text {, unperturbed) }\end{array}$ & $\begin{array}{l}1.0 \mathrm{E}+15 \\
(2.3 \mathrm{E}+14)\end{array}$ & $\begin{array}{l}3.0 \mathrm{E}+15 \\
(1.0 \mathrm{E}+15)\end{array}$ & \\
\hline Fast/thermal neutron flux ratio & $\begin{array}{c}>15 \\
(\mathrm{~N} / \mathrm{A})\end{array}$ & $\begin{array}{l}>100 \\
(\mathrm{~N} / \mathrm{A})\end{array}$ & \\
\hline $\begin{array}{l}\text { Flux uniformity in test space } \\
(\%)\end{array}$ & \pm 20 & \pm 5 & \\
\hline Peak fuel temperature $\left({ }^{\circ} \mathrm{C}\right)$ & 1,800 & 3,000 & \\
\hline $\begin{array}{l}\text { Peak fuel temperature } \\
\text { controllability - low } \\
\text { temperature (high } \\
\text { temperature) }\left({ }^{\circ} \mathrm{C}\right)\end{array}$ & $\pm 20( \pm 50)$ & $\pm 5( \pm 30)$ & $\begin{array}{c}\text { greater margin } \\
\text { at higher } \\
\text { temperatures }\end{array}$ \\
\hline $\begin{array}{l}\text { Surrounding gas temperature } \\
\left({ }^{\circ} \mathrm{C}\right)\end{array}$ & $280 \pm 5-1,100 \pm 7$ & $280 \pm 3-1,830 \pm 5$ & $\begin{array}{l}\text { greater margin } \\
\text { for higher } \\
\text { temperatures }\end{array}$ \\
\hline Loop gas pressure $(\mathrm{MPa})$ & 9 & 25 & \\
\hline Pressure controllability (\%) & \pm 3 & \pm 1 & \\
\hline Atmospheric compatibility & $\begin{array}{l}\mathrm{He}, \mathrm{Ne}, \mathrm{Ar}, \mathrm{Xe} \text {, and } \\
\text { mixtures thereof }\end{array}$ & Add $\mathrm{H}_{2}, \mathrm{CO}_{2}$ & \\
\hline $\begin{array}{l}\text { Gas flow to test chamber } \\
(\mathrm{mL} / \mathrm{min})\end{array}$ & $\begin{array}{l}\text { (Sufficient for } \\
\text { Reynolds number } \\
>10,000)\end{array}$ & & $\begin{array}{c}\text { See Section } \\
3.1 .9\end{array}$ \\
\hline \multicolumn{4}{|l|}{ Instrumentation } \\
\hline Temperature & $\begin{array}{c}15 \text { Channels } \\
10-1,400\left({ }^{\circ} \mathrm{C}\right)\end{array}$ & $\begin{array}{c}30 \text { Channels } \\
10-1,800\left({ }^{\circ} \mathrm{C}\right)\end{array}$ & $\begin{array}{c}\text { Higher } \\
\text { temperatures } \\
\text { may be }\end{array}$ \\
\hline
\end{tabular}




\section{CONTENTS}

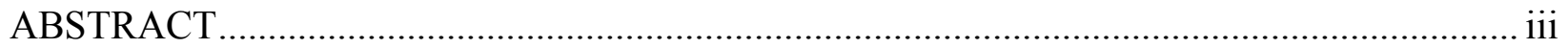

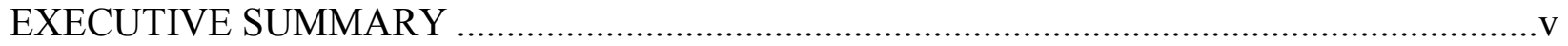

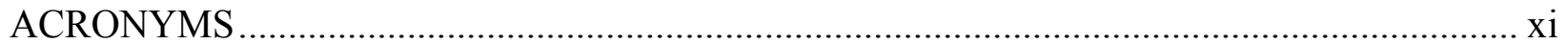

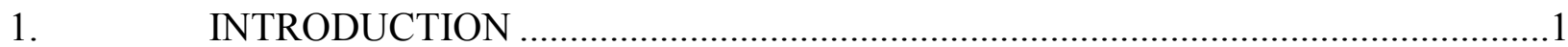

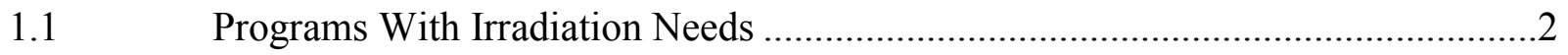

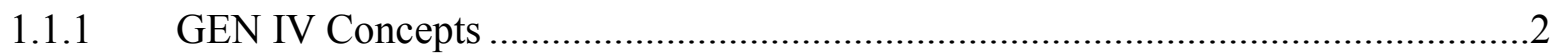

1.1.2 Space Nuclear Concepts ................................................................................2

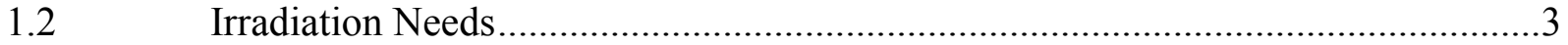

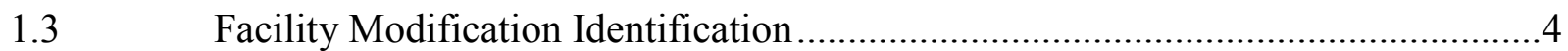

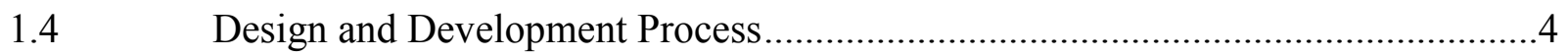

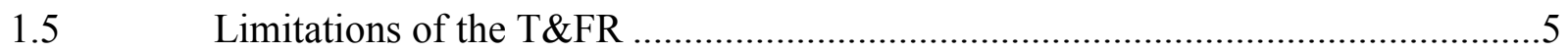

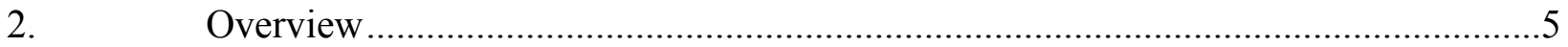

2.1 Facility, Structure, System, Component Functions ………………………….......5

2.2 Facility, Structure, System, Component Safety Category …………………….......5

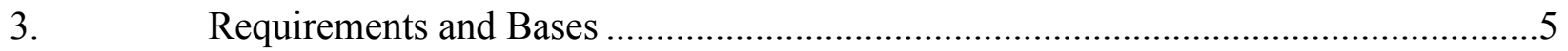

3.1 Functional and Performance Requirements .......................................................6

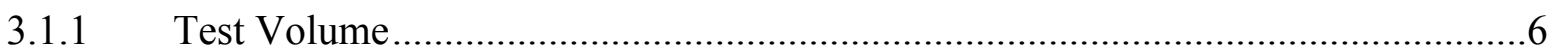

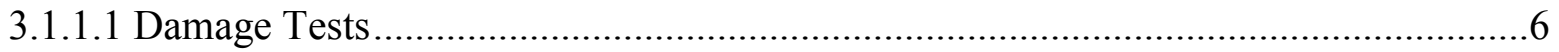

3.1.1.2 Transport Tests........................................................................................6

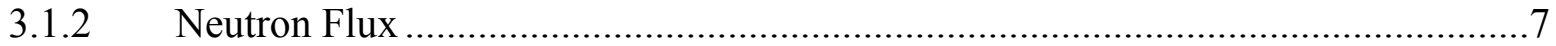

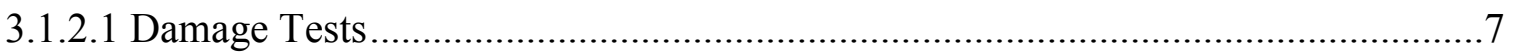

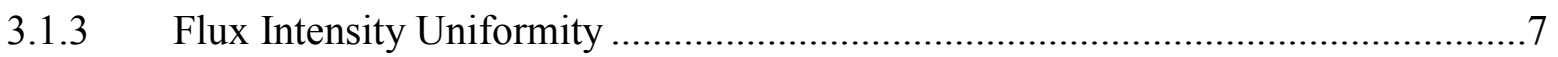

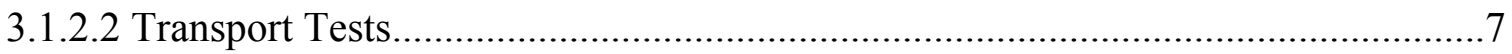

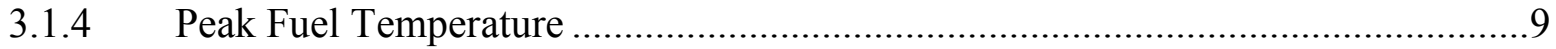

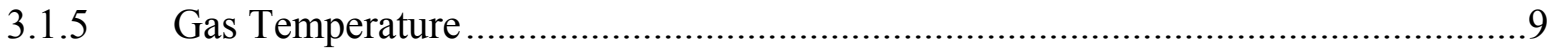

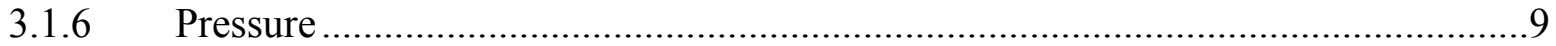

3.1.7 Pressure Controllability ............................................................................ 10

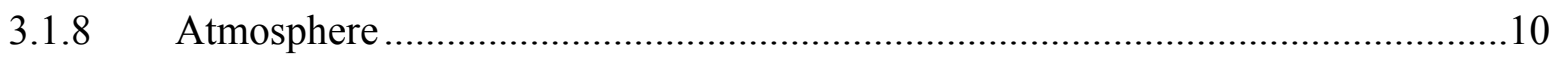

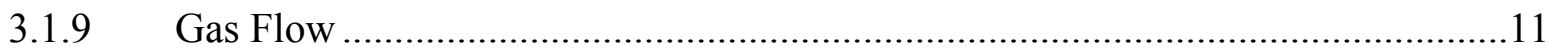

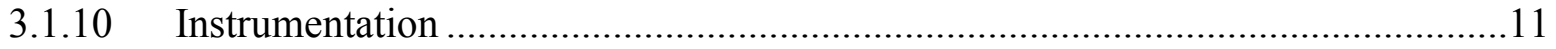

3.1.10.1 Temperature ……………………….............................................11

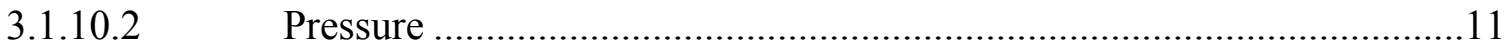




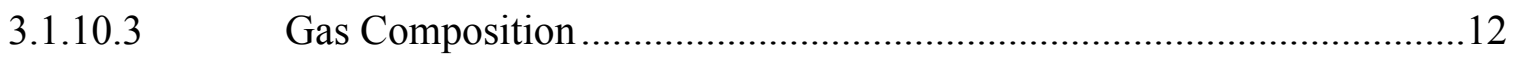

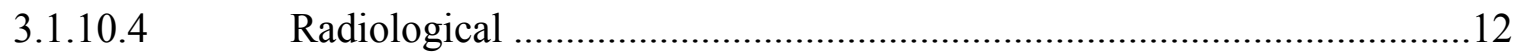

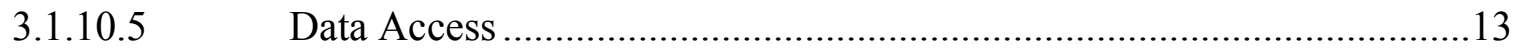

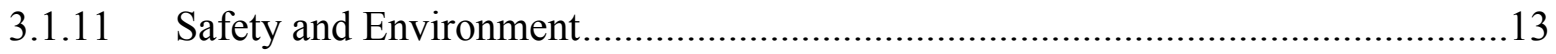

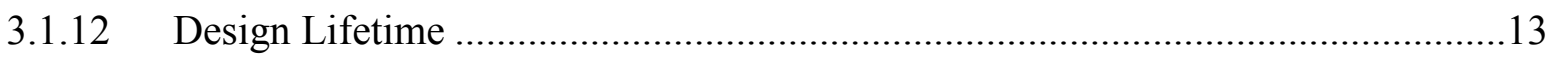

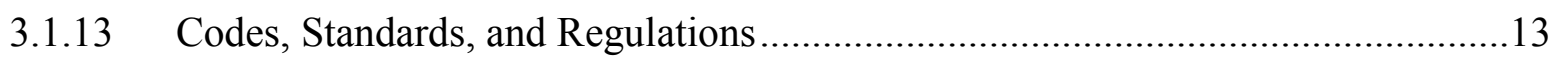

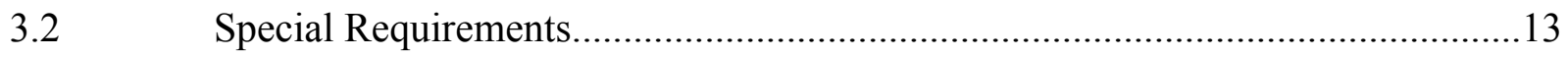

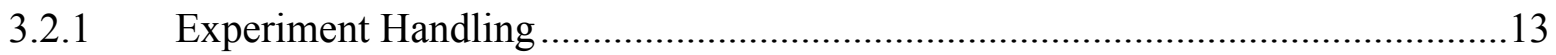

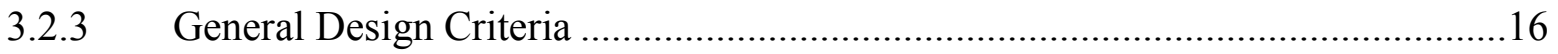

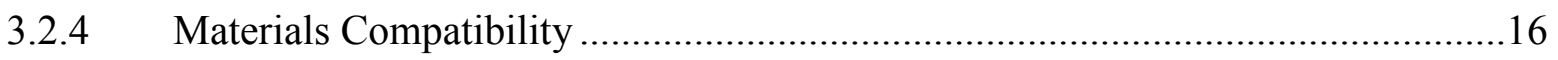

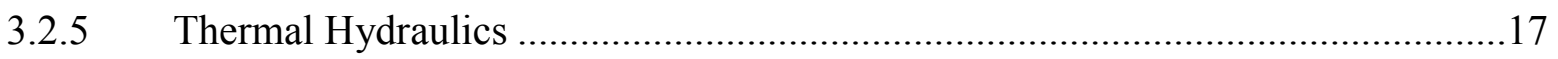

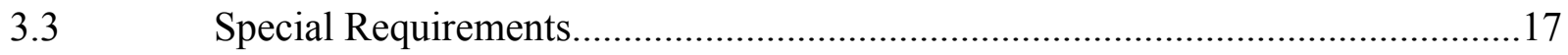

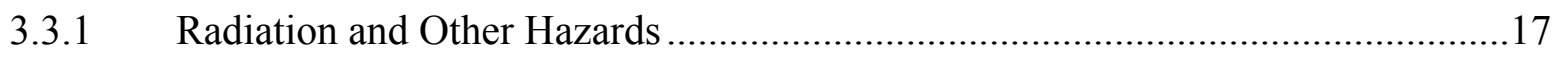

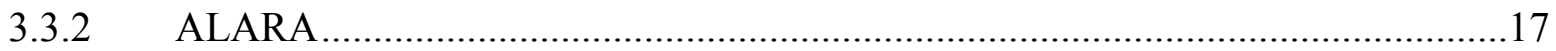

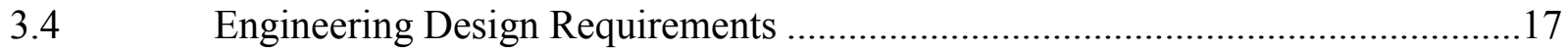

3.4.1 Mechanical Design Criteria-Code Compliance of Experiment

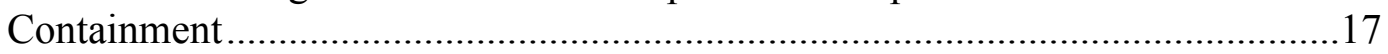

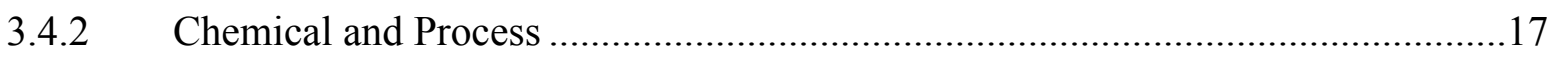

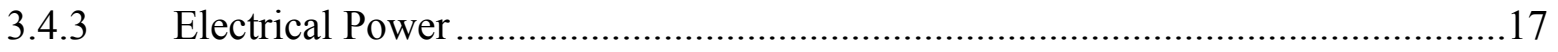

3.4.4 Measuring and Test Equipment ..........................................................................17

3.4.5 Computer Hardware and Software..................................................................

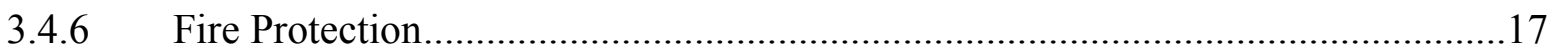

3.5 Testing and Maintenance Requirements .......................................................... 18

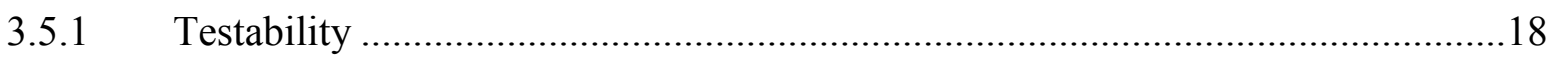

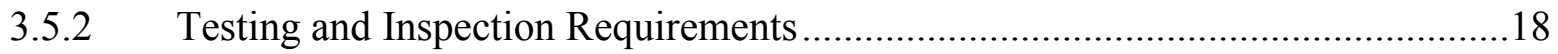

3.5.3 TSR-Required Surveillance .......................................................................18

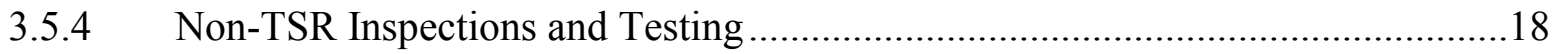

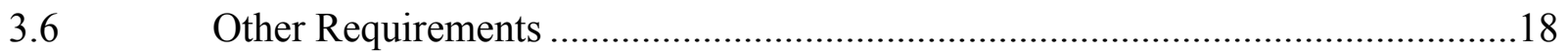

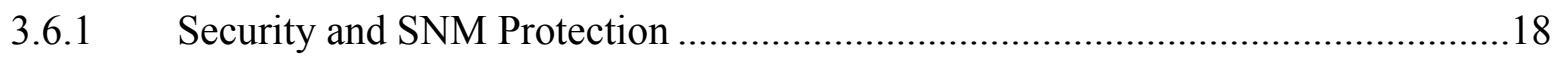

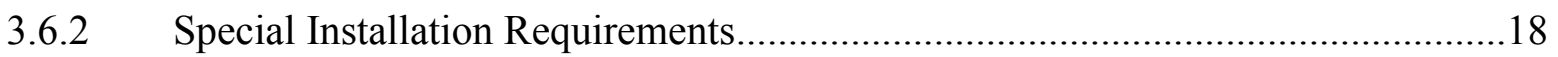

3.6.3 Common-Mode Failures ................................................................................

3.6.4 Availability and Reliability ......................................................................18

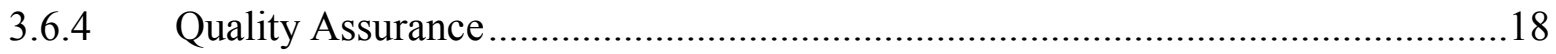




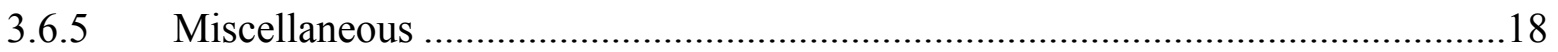

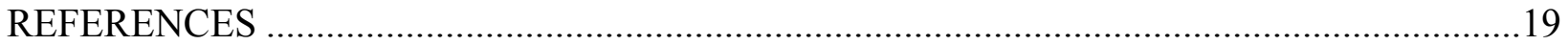

APPENDIX A GENERATION IV REACTOR CONCEPTS .................................................21

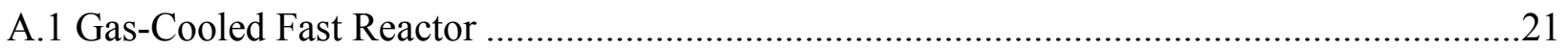

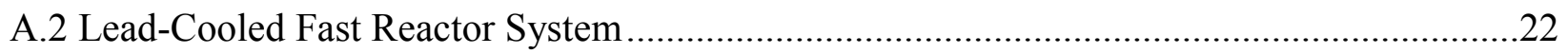

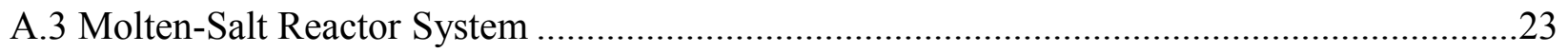

A.4 Sodium-Cooled Fast Reactor System ……………..........................................................23

A.5 Supercritical-Water-Cooled Reactor System ……………................................................24

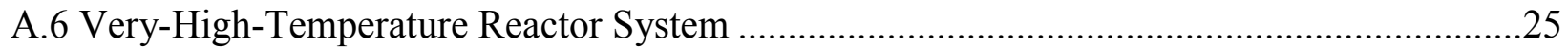

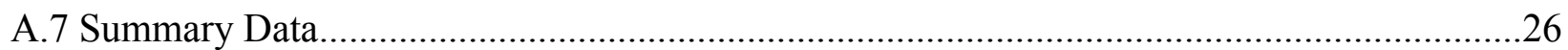

FIGURES

Figure 1. Design of the Gas Test Loop requires coordination at many levels................................ 4

Figure 2. Comparison of fast-fission spectrum (LMFBR) with typical thermal fission spectrum from ATR showing required and desired thermal flux suppression for fast-fission spectrum

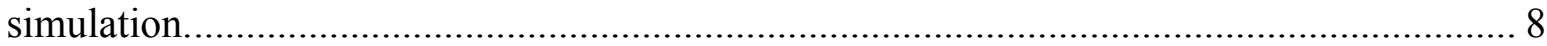

\section{TABLES}

Table 1. Summary of features required by the Gas Test Loop. Values in parentheses refer specifically to test implementations where evolution and transport of fission fragments and activation products are the main concerns. Not every requirement will apply to each implementation. ....................................................... vi

Table 2. Principal characteristics and operating environments for the Gen IV reactors. .................3

Table 2. Summary of codes, standards, and regulations applicable ${ }^{a}$ to the design of the

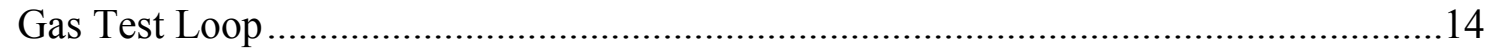

Table A-1. Design parameters for the Gas-Cooled Fast Reactor system. ......................................21

Table A-2. Design parameters for the Lead-Cooled Fast Reactor system.......................................22

Table A-3. Design parameters for the Sodium-Cooled Fast Reactor system. ………....................23

Table A-4. Design parameters for a thermal-spectrum Supercritical Water Reactor

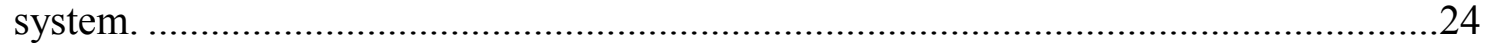

Table A-5. Summary of design parameters for the Very-High-Temperature Reactor

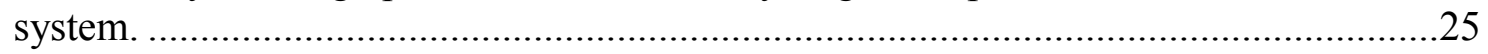

Table A-6. Fuel and structural material options for the various GEN IV reactors........................26

Table A-7. Design features of Generation IV reactor options....................................................27 


\section{ACRONYMS}

ALARA as low as reasonably achievable

ASME American Society of Mechanical Engineers

AFCI Advanced Fuel Cycle Initiative

CFR Combined Federal Regulations

CRD Contractor Requirements Document

DOE U.S. Department of Energy

EBR II Experimental Breeder Reactor II

GEN IV Generation IV Reactor Program

GFR Gas-Cooled Fast Reactor

GTL Gas Test Loop

HTGR High Temperature Gas Reactor

LFR Lead-Cooled Fast Reactor

M\&TE measuring and test equipment

MOX mixed oxide

MSR Molten-Salt Reactor

NASA National Aeronautics and Space Administration

NBS National Bureau of Standards

NERAC Nuclear Energy Research Advisory Committee

NFPA National Fire Protection Association, Inc.

NGNP Next Generation Nuclear Plant

NHI Nuclear Hydrogen Initiative

NIST National Institute of Standards and Technology

NRC Nuclear Regulatory Commission

NUREG Nuclear Regulatory Commission report

PCS primary coolant system

SCWR Supercritical-Water-Cooled Reactor

SFR Sodium-Cooled Fast Reactor

SSC system, subsystem, or component

TBD to be determined

TRU transuranic

TSR technical safety requirement

VHTR Very-High-Temperature Reactor 


\section{INTRODUCTION}

The U.S. Department of Energy (DOE) has determined that there is a need for a nuclear fuels and materials testing capability, or Gas Test Loop (GTL), in which irradiation testing can be performed for advanced fission reactors. ${ }^{1}$ The Advanced Fuel Cycle Initiative (AFCI) has a broad charter to advance nuclear power, particularly by finding a way to close the nuclear fuel cycle or significantly reduce the amount of nuclear waste from reactors. The Generation IV Advanced Reactor Program (GEN IV) is the program that will be developing a number of reactor concepts needed for sustainable nuclear power.

The May 2001 National Energy Policy recommended that the U.S. develop advanced reprocessing and fuel technologies and an expansion of nuclear energy that are cleaner, more efficient, less waste intensive, and more proliferation resistant. These technologies are the key components of advanced nuclear fuel cycles that will be needed for next generation nuclear energy systems. To address these challenges, the Office of Advanced Nuclear Research (DOE/NE-20) has adopted an integrated strategy consisting of the GEN IV, the Nuclear Hydrogen Initiative (NHI), and the AFCI. The GEN IV-AFCI integrated program will develop the next generation of nuclear energy systems, capable of providing energy for generations of Americans. AFCI is closely coupled with the GEN IV Nuclear Energy Systems Initiative, which seeks to deploy a new generation of power plants by 2030 . Together, these two programs enable an expanded role for nuclear power as a greenhouse-emission-free, sustainable energy resource that will address long-term U.S. energy security, environmental, and economic concerns.
The mission of the AFCI is to develop proliferation-resistant spent nuclear fuel treatment and transmutation technologies in order to enable a transition from the current once through nuclear fuel cycle to a sustainable, closed nuclear fuel cycle. The primary goals of the AFCI program are to:

- Develop technologies that will reduce the cost of geological disposal of high-level waste from spent nuclear fuel, enhancing the repository performance.

The U. S. currently stores more than 46,000 metric tons (tonnes) of spent nuclear fuel at commercial nuclear power plants, and $\sim 103$ operating reactors generate an aggregate of approximately 2,000 tonnes of additional spent fuel each year. At this generation rate, the statutory limit of 63,000 tonnes allocated for civilian spent nuclear fuel within the planned geologic repository will be reached by 2015 .

- Enable proliferation resistant recovery of energy contained in spent fuel.

By 2003, 460 tonnes of plutonium inventory would have already accumulated in commercial spent fuel in the U.S. alone and in 2015, the plutonium inventory would reach 750 tonnes. The U.S. has become increasingly concerned about the global accumulation of plutonium, which presents an important proliferation risk worldwide.

- Develop reactor fuel and fuel cycle technologies to support GEN IV nuclear energy systems.

Improved use of energy resources, such as the plutonium and uranium in spent fuel, is an important element of a sustainable energy strategy. If the Secretary of Energy's Nuclear Power 2010 Initiative is successful, the U.S. will start building new nuclear power facilities within the next ten years 
that will operate until at least 2070

depending on fuel cycle.

The AFCI research and development program is an integrated research effort aimed at addressing both intermediate-term and long-term issues.

The Generation IV International Forum, along with U. S. DOE's Nuclear Energy Research Advisory Committee (NERAC), has published "A Technology Roadmap for Generation IV Nuclear Energy Systems"a . It has identified six advanced reactor designs that offer the promise of commercial deployment before 2030 . Several of these designs use fuel cycles significantly different from those used by existing U.S. reactors. Although various fuel types have been proposed for these reactors, the final fuels that will be demonstrated have not yet been designed, fabricated, tested or qualified.

A fuel development and qualification program is underway to fabricate, irradiate and perform post-irradiation simulated operating and accident conditions testing. The test fuels will be used to verify that fuels manufactured under reference process conditions perform satisfactorily under the full range of normal operating and accident conditions. This work will require significant resources over an extended period with a goal to qualify and fabricate the first GEN IV reactor fuel by 2011 .

\footnotetext{
${ }^{a}$ The GEN IV International Forum includes ten countries-Argentina, Brazil, Canada, France, Japan, the Republic of Korea, the Republic of South Africa, Switzerland, the Untied Kingdom, and the United States.
}

\subsection{Programs With Irradiation Needs}

\subsubsection{GEN IV Concepts}

The GEN IV program identified the following six reactor concepts.

- Lead-Cooled Fast Reactor (LFR)

- Molten-Salt Reactor (MSR)

- Sodium-Cooled Fast Reactor (SFR)

- Supercritical-Water-Cooled Reactor (SCWR)

- Very-High-Temperature Reactor (VHTR)

- Gas-Cooled Fast Reactor (GFR)

Brief descriptions of the Gen IV reactor concepts are provided in Appendix A. Table 2 lists the principal characteristics and operating environments associated with these various designs.

\subsubsection{Space Nuclear Concepts}

Another important initiative is the determination by the National Aeronautics and Space Administration (NASA) to make use of nuclear reactor power for space applications. ${ }^{2}$ These may be vehicle power systems to provide propulsion in deep space where conventional fuels and solar power will be ineffective, or they may include modular surface power systems for supplying energy needs for exploration. Propulsion may be nuclear electric, in which the reactor is used to generate electricity to be used with an ion propulsion system; nuclear thermal, where the reactor heats hydrogen and expels it to provide thrust; or a combination of nuclear thermal propulsion and secondary electric power generation in a bi-modal reactor concept. This program is a potential customer for the GTL. 
Table 2. Principal characteristics and operating environments for the Gen IV reactors. ${ }^{3}$

\begin{tabular}{|c|c|c|c|c|c|}
\hline Concept & Flux & Coolant & $\begin{array}{c}\text { Coolant } \\
\text { Outlet } \\
\text { Temperature } \\
\left({ }^{\circ} \mathrm{C}\right)\end{array}$ & $\begin{array}{c}\text { Coolant } \\
\text { Pressure } \\
\text { (MPa) }\end{array}$ & $\begin{array}{l}\text { Fuel } \\
\text { Form }\end{array}$ \\
\hline LFR & fast & $\mathrm{Pb} / \mathrm{Pb}-\mathrm{Bi}$ & $500-800$ & 0.1 & $\begin{array}{l}\text { clad } \\
\text { pellets }\end{array}$ \\
\hline MSR & $\begin{array}{l}\text { epithermal/ } \\
\text { thermal }\end{array}$ & $\mathrm{NaF}, \mathrm{ZrF}_{4}$ & $750-800$ & 0.01 & $\begin{array}{l}\text { molten } \\
\mathrm{UF}_{6} / \mathrm{ThF}\end{array}$ \\
\hline SFR & fast & $\mathrm{Na}$ & 550 & 0.1 & $\begin{array}{l}\text { clad } \\
\text { pellets }\end{array}$ \\
\hline SCWR & thermal & $\begin{array}{l}\text { Supercritical } \\
\mathrm{H}_{2} \mathrm{O}\end{array}$ & 510 & 25 & $\begin{array}{l}\text { clad } \\
\text { pellets }\end{array}$ \\
\hline VHTR & fast & $\mathrm{He}$ & 1,000 & $\begin{array}{c}5-8 \\
\text { (process } \\
\text { dependent) }\end{array}$ & $\begin{array}{l}\text { blocks, } \\
\text { pins, or } \\
\text { pebbles }\end{array}$ \\
\hline GFR & fast & $\mathrm{He}$ & 850 & $7-9$ & $\begin{array}{l}\text { pebbles } \\
\text { or clad } \\
\text { pellets }\end{array}$ \\
\hline
\end{tabular}

\section{$1.2 \quad$ Irradiation Needs}

All these programs will have needs for irradiation testing of advanced fuels and materials in an environment representative of the environment of their intended service. For some tests, the main concern will be the effects of neutrons on reactor fuels and structural materials. In other tests, the focus will be on the emission and transport of fission and activation products from the fuel assemblies.

The need for a GTL capability has been established within DOE-NE. ${ }^{1}$ A single GTL may not meet all the needs of all the programs because, as evident in Table 2, the needs of the various programs differ.
Examination of Table 2 suggests two kinds of testing will be needed.

In one, the main focus will be on neutron irradiation effects on fuels and materials. There, the key capabilities will include intense neutron flux of appropriate energies and the ability to achieve the desired temperatures and temperature gradients in the test articles.

In the other main category of testing, attention will focus on appropriate coolant/material interactions and the transport of any evolved fission or activation products through the cooling system.

Combined, these two testing capabilities will 


\begin{tabular}{|c|c|c|c|}
\hline Parameter & Required & Desired & Comments \\
\hline & & & $\begin{array}{c}\text { witnessed by } \\
\text { melt wires }\end{array}$ \\
\hline Pressure & $\begin{array}{c}3 \text { channels internal } \\
10 \text { channels external } \\
0-9(\mathrm{MPa}), \pm 3 \%\end{array}$ & $\begin{array}{c}5 \text { channels internal } \\
10 \text { channels external } \\
0-25(\mathrm{MPa}), \pm 3 \%\end{array}$ & \\
\hline Gas composition & $\begin{array}{c}3 \text { channels internal } \\
10 \text { channels external } \\
\text { down to } 1(\mathrm{mg} / \mathrm{kg}) \\
\pm 3 \%\end{array}$ & $\begin{array}{c}5 \text { channels internal } \\
10 \text { channels external } \\
\text { down to } 0.11 \\
(\mathrm{mg} / \mathrm{kg}), \pm 3 \%\end{array}$ & $\begin{array}{c}\text { Fully } \\
\text { independent }\end{array}$ \\
\hline Radioassay & $\begin{array}{c}\text { Determined by } \\
\text { experiment }\end{array}$ & $\begin{array}{c}\text { On-line } \\
\text { spectrometry }\end{array}$ & \\
\hline Data access & \multicolumn{2}{|c|}{ Remote real-time visibility } & \\
\hline Safety and environment & \multicolumn{2}{|c|}{$\begin{array}{c}\text { Avoid hazardous-mixed waste generation } \\
\text { Two levels of confinement } \\
\text { Automatic safe shutdown } \\
\text { Shielded container }(<200 \mathrm{mR} / \mathrm{hr})\end{array}$} & \\
\hline Design Lifetime (years) & 30 & Life of Program & $\begin{array}{l}\text { Component } \\
\text { replacement } \\
\text { acceptable }\end{array}$ \\
\hline
\end{tabular}

This list of requirements is not exhaustive. In addition to the specific and quantitative requirements identified here, regulatory and facility interface requirements will be imposed. These may include requirements for physical fit, compliance with facility Technical Safety Requirements, and compliance with criteria and assumptions in the facility Safety Analysis Report. 
provide a versatile resource within which to advance technology and science.

\subsection{Facility Modification Identification}

The requirements for the GTL system do not necessarily require the modification of any facility. Rather, the GTL system consists of assemblies that can be installed in an existing irradiation facility. Such a facility may be a nuclear reactor or a beam facility capable of meeting the functional requirements defined below.

\subsection{Design and Development Process}

The process of identifying requirements and a producing a design is an interactive one. Basic performance goals come from the known or potential customers for the capability. Program requirements must then be tempered by the physical and operational limitations of the host facility. There will necessarily be continuous communication and negotiation among these entities. These relationships are illustrated in Figure 1.

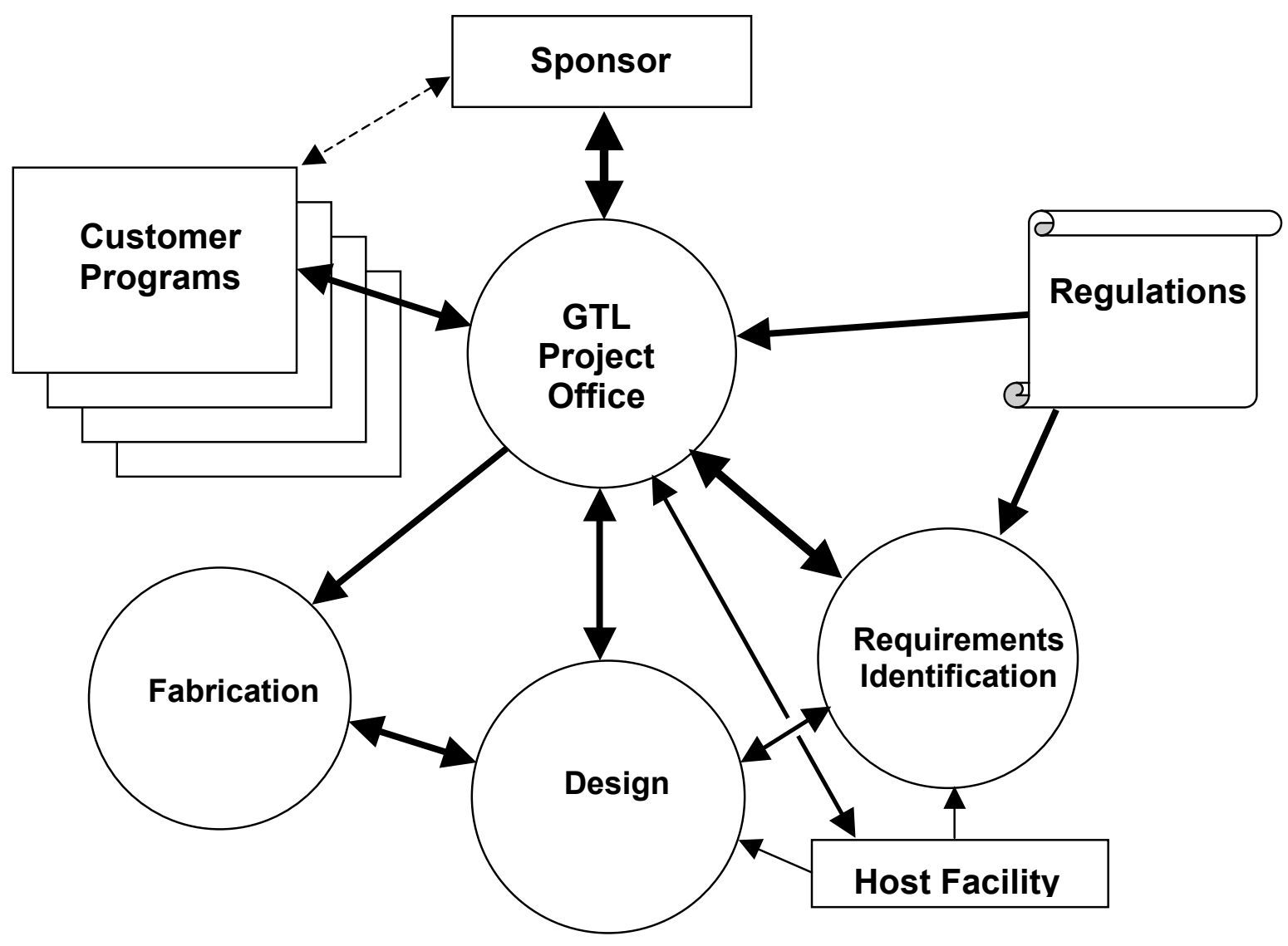

Figure 1. Design of the Gas Test Loop requires coordination at many levels. 


\subsection{Limitations of the T\&FR}

The requirements identified in this document are for the performance and operational characteristics of the GTL assemblies. They do not include the many derived requirements associated with installation into any given irradiation facility, nor do they include requirements on the project team with regard to such things as records management, data security, conduct of operations, or integrated safety management.

This document is promulgated by the Fission and Fusion Systems Department of the Nuclear Science and Engineering Directorate at the Idaho National Engineering and Environmental Laboratory.

The purpose of this document is to identify the technical and functional requirements for the GTL. It is intended to be a "living document" (go through several drafts in the process of ultimate completion). When finalized, it will form the basis for the design.

\section{Overview}

\subsection{Facility, Structure, System, Component Functions}

The GTL, in its various

implementations, will provide a testing environment for fuels and materials of interest to the nuclear community. It is being constructed with particular emphasis on the GEN-IV programs. The testing environments to be provided may include neutron irradiation and gaseous atmospheric control representative of service conditions in the reactors being considered by the programs the GTL will support. Not every aspect of the service environment will need to be included in each GTL implementation. The GTL will also gather information on test articles and the test environment and provide these data to experimenters.

\subsection{Facility, Structure, System, Component Safety Category}

The GTL is not a Safety-Class system, subsystem, or component (SSC) ${ }^{\mathrm{b}}$ per se, but any part of the GTL that provides a primary coolant or radioactivity containment boundary for the irradiation facility shall be Safety Class. SSCs that do not constitute a primary pressure or confinement boundary shall be Safety-Significant ${ }^{\mathrm{c}}$ because their failure could threaten the safety of the facility in which the SSC is installed.

\section{Requirements and Bases}

The requirements presented below are to define ranges over which test parameters may vary. It is important to reiterate that not every test implementation will require parameters at the extremes of the values provided below. Note, for example, in Table 2, that the GFR requires $9 \mathrm{MPa}$ of pressure capability but only $850^{\circ} \mathrm{C}$ coolant exit temperature. The VHTR, on the other hand, requires $1,000^{\circ} \mathrm{C}$ capability in temperature, but the required pressures will vary dependent on the process the VHTR will be supporting. The GFR and VHTR both require a fast neutron flux, but MSR and SCWR make use only of thermal or epithermal neutron fluxes. Hence, the particular set of capabilities built into a

\footnotetext{
${ }^{\mathrm{b}}$ Safety class structures, systems, and components means the structures, systems, or components, including portions of process systems, whose preventive or mitigative function is necessary to limit radioactive hazardous material exposure to the public, as determined from safety analyses (10 CFR 830.3)

c Safety significant structures, systems, and components means the structures, systems, and components which are not designated as safety class structures, systems, and components, but whose preventive or mitigative function is a major contributor to defense in depth and/or worker safety as determined from safety analyses (10 CFR 830.3)
} 
particular GTL implementation will depend on the program it is supporting.

\subsection{Functional and Performance Requirements}

Based on the anticipated and stated programmatic needs of potential users, the following are limits of parameters the may constitute requirements for GTL's technical performance. Requirements listed in the following sections are minimum acceptable features and correspond to shalls in conventional parlance. Desired features would provide benefit but are not necessarily required. They represent extensions in capability, the incorporation of which is optional.

\subsubsection{Test Volume}

The test volume required depends on the nature of the tests being performed. Tests of fuel or material damage from irradiation can be made on small fuel rod segments or mechanical test specimens. Tests that involve evolution and transport of fission and activation products will require prototypic structures that will generally be larger.

\subsubsection{Damage Tests}

Requirement: The test chamber volume shall accommodate specimens $15.5 \mathrm{~cm}$ long and $2.54 \mathrm{~cm}$ diameter.

\section{Basis}

The GTL justification document ${ }^{1}$ indicates that for GEN IV/AFCI, the volume must be able to accommodate $15.5-\mathrm{cm}$ (6inch) long fuel pins of $\sim 1 \mathrm{~cm}^{2}$ cross-sectional area, 2.5-cm (1-inch) diameter test wafers, or possibly fuel pebbles (6-cm spheres).

That is a clear volume, independent of any other volume required for instrumentation, cooling systems, gas flow paths, radioactivity containment boundary, etc. It is a test volume appropriate for irradiation damage testing of clad pellet type fuel and mechanical test specimens of other reactor materials.

\section{Desired: Accommodate test specimens $40 \mathrm{~cm}$ long.}

\section{Basis}

Fuel rods in most reactor designs will be longer than $15.5 \mathrm{~cm}$. Greater test volume length will accommodate longer test specimens or multiple specimens. The desired length of $40 \mathrm{~cm}$ is based on the position of the $90 \%$ flux intensity points above and below core mid-plane in a typical research reactor.

\section{Desired: Accommodate test specimens $61 \mathrm{~cm}$ long and $5 \mathrm{~cm}$ in diameter.}

\section{Basis}

Space nuclear fuel elements may be as long as $61 \mathrm{~cm}$ and as large as $5 \mathrm{~cm}$ in diameter.

\subsubsection{Transport Tests}

\section{Requirement: The test chamber volume shall accommodate specimens $15.5 \mathrm{~cm}$ long and $6 \mathrm{~cm}$ diameter.}

\section{Basis}

GFR and possibly VHTR pebbles are planned to be $6 \mathrm{~cm}$ in diameter. The $15.5-\mathrm{cm}$ length would accommodate the same test articles as those addressed in paragraph 3.1.1.1 Damage Tests.

\section{Desired: Accommodate test specimens $61 \mathrm{~cm}$ long.}

\section{Basis}

Space nuclear fuel elements may be as long as $61 \mathrm{~cm}$ and as large as $5 \mathrm{~cm}$ in diameter. 


\subsubsection{Neutron Flux}

The characteristics of the neutron flux required will depend on the specific program and reactor concept for which the GTL implementation is designed. Here, flux requirements are grouped into damage testing and transport testing.

\subsubsection{Damage Tests}

Requirement: Provide a fast neutron flux $(E>0.1 \mathrm{MeV})$ of $1.0 \mathrm{E}+15 \mathrm{n} / \mathrm{cm}^{2}$-s with a fast/thermal ratio $>15$

\section{Basis:}

The justification document ${ }^{1}$ requires that fast neutron flux $(\mathrm{E}>0.1 \mathrm{MeV})$ shall be greater than $10^{15} \mathrm{n} / \mathrm{cm}^{2}-\mathrm{s}$. This is interpreted to mean that the mean value of the neutron flux intensity averaged over the test volume in an unperturbed flux (GTL assembly in place without test article present) shall be at least $1.0 \times 10^{15} \mathrm{n} / \mathrm{cm}^{2}$-s and that the fast to thermal flux intensity ration shall be at least 15 at all locations in the test volume.

\section{Desired: Provide a fast $(\mathrm{E}>\mathbf{0 . 1} \mathrm{MeV})$ neutron flux of $3.0 \mathrm{E}+15 \mathrm{n} / \mathrm{cm}^{2}$-s with a fast/thermal ratio $>100$.}

\section{Basis}

Higher flux rates mean shortened irradiation time to meet specific irradiation objectives. It is desired that the thermal neutron flux should be essentially absent, as in the typical fast reactor spectrum shown in Figure 2. ${ }^{4}$ A desired goal is shown as the lower dashed line in Figure 2. That goal has the thermal neutron flux no more than $1 \%$ of its intensity in the thermal fission spectrum. Values for flux intensity are for an unperturbed flux and averaged over the test volume. Fast to thermal ratio applies over the entire test volume.

\subsubsection{Flux Intensity Uniformity}

\section{Requirement: Flux intensity shall be} uniform within $20 \%$ over the specimen volume.

\section{Basis}

Anticipated requirements of experimenters are that at no point in the test volume shall the intensity of the neutron flux in an unperturbed test space depart by more than $20 \%$ from the mean value over the test space.

\section{Desired: Provide flux intensity uniformity of $\pm 5 \%$ averaged over the test space.}

\section{Basis}

Except when flux gradient effects are of specific interest, experimenters will want the neutron flux over the volume of a test specimen to be as uniform as possible to allow correlation of results with theories.

\subsubsection{Transport Tests}

\section{Requirement: Provide a total neutron flux of at least $2.3 \mathrm{E}+14 \mathrm{n} / \mathrm{cm}^{2}$-s.}

\section{Basis:}

Studies of evolution and transport of fission and activation products from fuels and other structures depend on fuel heating and power developed far more than on neutron energy spectra. Therefore, the only requirement with regard to neutron flux is for total available neutronic power. The required power level is typical of that anticipated in advanced reactor operating scenarios. This value is approximately that for a prismatic VHTR.

\section{Requirement: Provide a total neutron flux of at least $1.0 \mathrm{E}+15 \mathrm{n} / \mathrm{cm}^{2}$-s.}




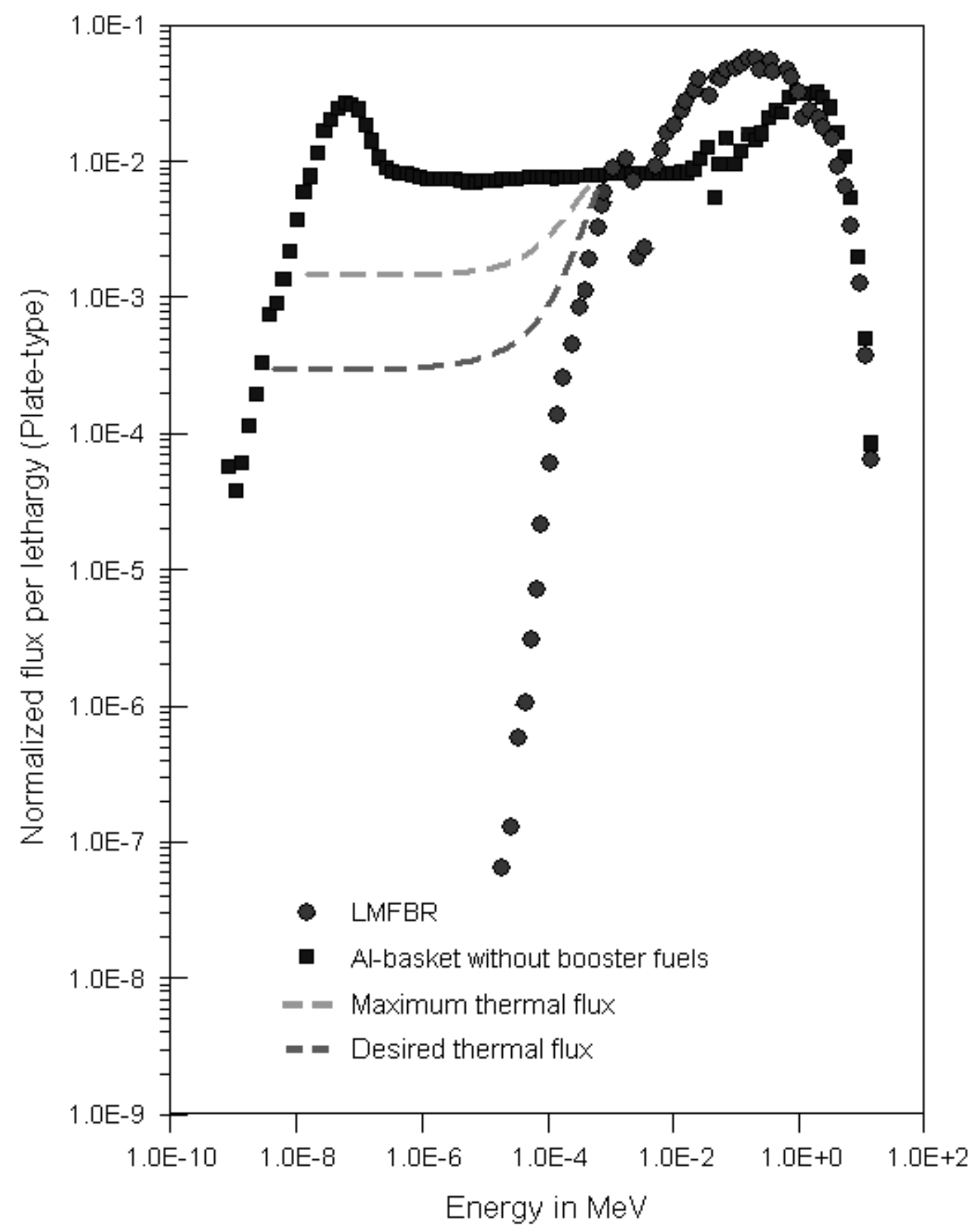

Figure 2. Comparison of fast-fission spectrum (LMFBR) with typical thermal fission spectrum from ATR showing required and desired thermal flux suppression for fast-fission spectrum simulation. 


\section{Basis:}

Higher flux than expected operating conditions will allow accelerated testing to be conducted. The actual goal is imprecise.

\subsubsection{Peak Fuel Temperature}

The peak fuel temperature requirement will depend on the reactor concept being tested. Listed here are the extreme values that could be needed. The extreme temperatures will not be needed in all GTL implementations.

Requirement: Provide test conditions that will support a centerline temperature in experimental fuel of $1800{ }^{\circ} \mathrm{C}$, controllable to $\pm 20^{\circ} \mathrm{C}$. Desired controllability is $\pm 5^{\circ} \mathrm{C}$.

Basis

$1,800^{\circ} \mathrm{C}$ is the temperature required for a survivable accident in the VHTR. ${ }^{5}$ Controllability requirement is based on anticipated needs of experimenters.

Desired: Provide test conditions that will support an experimental fuel centerline temperature of $3,000{ }^{\circ} \mathrm{C}$, controllable to $\pm 50{ }^{\circ} \mathrm{C}$. Desired controllability is $\pm 30{ }^{\circ} \mathrm{C}$

\section{Basis}

$3,000^{\circ} \mathrm{C}$ for peak fuel temperature is that anticipated for nuclear-thermal rocket fuel. ${ }^{6}$ Temperatures that high will be unlikely to achieve the same controllability as lower temperatures. Values given are estimates of attainable controllability and anticipated experimenter desires.

\subsubsection{Gas Temperature}

The requirements for temperature of the gases surrounding test articles will depend on the reactor concept being tested. Listed here are the extreme upper and lower values that could be needed. The extreme temperatures will not be needed in all GTL implementations (see Table 2).

Requirement: Provide the means of achieving temperature in the gases surrounding the test article of $280 \pm 5{ }^{\circ} \mathrm{C}$ to $1,100 \pm 7^{\circ} \mathrm{C}$.

\section{Basis}

The temperature of the gas surrounding the test article in the GTL system shall be controllable between temperatures of $280^{\circ} \mathrm{C}$ and $1,100^{\circ} \mathrm{C}$, depending on the particular implementation. The upper end of that range derives from the VHTR, where the design core outlet temperature is $1,000^{\circ} \mathrm{C}$. There must be capability to exceed the maximum test temperature by a sufficient amount that modest excursions $(10 \%)$ from nominal heat loads will not cause the system to fail. The lower end of the controllable gas temperature range is the coolant inlet temperature of the SCWR. ${ }^{7}$ Controllability is based on the anticipated needs of experimenters and estimates of capability.

Desired: Provide the means of achieving temperature in the gas surrounding the test article to $1,830 \pm 10{ }^{\circ} \mathrm{C}$.

\section{Basis}

The desired goal for the maximum controllable surrounding gas temperature of $1,830^{\circ} \mathrm{C}$ comes from space nuclear power needs. A near-term space reactor turbine inlet temperature of $1,650^{\circ} \mathrm{C}$ has been discussed with $1,830^{\circ} \mathrm{C}$ as a goal in the intermediate future. ${ }^{8}$ Controllability requirement is based on the anticipated needs of experimenters and estimates of capability.

\subsubsection{Pressure}

Pressures required will depend on the specific reactor concept addressed by the 
GTL implementation. Extremes are listed here.

Requirement: Provide the means for achieving pressure in the gas surrounding the test article up to $9 \mathrm{MPa}$.

Basis

Pressures identified for several of the reactors whose fuel would be tested in the GTL are listed in Table 2. The basis of the required value is the operating pressure of the GFR.

Desired: Provide the means for achieving pressure in the gas surrounding the test article up to $25 \mathrm{MPa}$.

\section{Basis}

The desired goal is that used in the SCWR, as listed in Table 2. It should be noted that testing SCWR concepts may involve surrogates for the supercritical water coolant

\subsubsection{Pressure Controllability}

Requirement: Provide the means to control gas pressure to $\pm 3 \%$.

\section{Basis}

This requirement is based on anticipated needs of experimenters and present capability.

Desired: Provide the means for controlling gas pressure to $\pm 1 \%$.

\section{Basis}

This requirement is based on anticipated needs of experimenters and desired capability.

\subsubsection{Atmosphere}

\section{Requirement: The GTL shall be} compatible with $\mathrm{He}$, $\mathrm{Ne}$, Ar, $\mathrm{Xe}$, and mixtures thereof.

\section{Basis}

Most of the advanced gas reactors use helium as the coolant. This is mainly due to its chemical stability at high temperatures and very low potential for materials degradation. Mixtures of He with heavy inert gases are used to control thermal conductance across gas gaps.

\section{Desired: The GTL shall also be compatible with $\mathrm{H}_{2}$, and $\mathrm{CO}_{2}$.}

\section{Basis}

The nuclear-thermal propulsion reactors use hydrogen because of its ability to maximize specific impulse. The hydrogen tank also is an excellent neutron shield.

The goal for $\mathrm{CO}_{2}$ compatibility comes from anticipated research that could lead to improved plant efficiencies using a supercritical $\mathrm{CO}_{2}$ Brayton cycle turbine. ${ }^{9}$ Because of its dissociation at temperatures above $700^{\circ} \mathrm{C}$, compatibility with $\mathrm{CO}_{2}$ would not be over the full range of operating temperatures.

\section{Desired: The GTL shall also be compatible with supercritical water.}

Supercritical water appears in Table 2, but compatibility is closely tied to the pressure capabilities of the GTL implementation. Only if pressures that will support supercritical water are attainable and manageable, would compatibility with this fluid be considered. Dissociation to oxygen and hydrogen becomes an issue at high temperatures in this fluid. 


\subsubsection{Gas Flow}

Requirements for gas flow are determined by the nature of the testing to be performed. For damage tests, flow will generally not be required except as a tool to control test article temperature by varying gas mixtures. That is not considered a requirement of the GTL but a means of meeting the temperature controllability requirement. Therefore, the following applies only to transport test implementations.

Requirement: Gas flow to and from the irradiation volume shall be provided with a minimum flow rate sufficient to produce Reynolds numbers of 10,000 or greater in the vicinity of the test article.

\section{Basis}

The capability shall be provided for the GTL to have gas flowing to the test chamber in those tests where evolution and transport of fission and activation products are primary test objectives. This is necessary to allow gas sampling for determining fission product release and gathering evidence of other activity. The requirement is set by anticipated experimenter needs for fully turbulent flow to maximize heat and mass transfer from the test articles and adjacent ducts.

\subsubsection{Instrumentation}

Instrumentation shall be provided in the following areas, to the precisions indicated.

\subsubsection{Temperature}

Requirement: Provide temperature measurement capability in the irradiation volume with at least 15 channels, capable of measuring temperatures from 10 $1,400{ }^{\circ} \mathrm{C}$, with resolution of $\pm 5^{\circ} \mathrm{C}$ to $500{ }^{\circ} \mathrm{C}$ and $\pm 1.0 \%$ above $500{ }^{\circ} \mathrm{C}$
Basis

Temperatures of gases, selected surfaces, and at selected internal points shall be measured to a precision of $\pm 5^{\circ} \mathrm{C}$ at temperatures to $500^{\circ} \mathrm{C}$. Above $500^{\circ} \mathrm{C}$, temperature measurement precision shall be within $1.0 \%$. As a minimum, 15 channels of temperature data shall be provided. The basis of these requirements is anticipated needs of experimenters and current state-ofthe-art in temperature collection.

Desired: Provide temperature measurement capability in the irradiation volume with at least 30 channels, capable of measuring temperatures from 10 $1,800{ }^{\circ} \mathrm{C}$, having a resolution of $\pm 2.5^{\circ} \mathrm{C}$ to $1,000{ }^{\circ} \mathrm{C}$ and $\pm 0.5 \%$ above $1,000{ }^{\circ} \mathrm{C}$.

Basis

A desired goal is for 30 channels of temperature data to be available. The desired goal is for temperature precision of $\pm 2.5^{\circ} \mathrm{C}$ to $1,000^{\circ} \mathrm{C}$ and $\pm 0.5 \%$ above that temperature. It is recognized that different experiments may use different means of temperature measurement, depending on the temperature ranges of interest in those experiments. For temperatures not measurable in real time using available technologies, temperature witness samples(melt wires) may be considered.

\subsubsection{Pressure}

Requirement: Provide pressure measurement capability with 3 channels internal to the test volume and 10 channels external to the test volume with a range of 0- $9 \mathrm{MPa}$ and a resolution of $\pm 3 \%$.

\section{Basis}

Means shall be provided to monitor at least 3 channels of pressure measurements 
inside the test space of the GTL to a precision of $\pm 3 \%$ over the range of pressures measured. Minimum required upper pressure limit is $9 \mathrm{MPa}$. This is in addition to at least 10 other channels of pressure data that may be gathered outside the test space. For designs where all gases are flowing or are otherwise connected to the outside of the GTL, measurements made outside the test loop can be made to suffice. However, for restricted flow passages or where gas volumes are not connected with the outside of the test space, there will be a need to collect pressure information in the test space itself. Channel numbers and precision are based on anticipated experimenter needs and available pressure measurement technology.

Desired: Provide pressure measurement capability with 5 channels internal to the test volume and 10 channels external to the test volume, having a range of 0 - 25 MPa and a precision of $\pm 1 \%$.

\section{Basis}

A desired goal is that 5 channels of insitu pressure measurements be available. Desired upper pressure limit (see Table 2) is $25 \mathrm{MPa}$. Another desired feature is that precision of pressure measurement be within $\pm 1 \%$. Channel numbers and precision are based on anticipated experimenter needs and available pressure measurement technology.

\subsubsection{Gas Composition}

Required: Provide means for determining gas composition on 3 channels of flow to and from locations internal to the test volume and 10 channels for locations external to the test volume, with a sensitivity of $1 \mathrm{mg} / \mathrm{kg}$ and a precision of $\pm 3 \%$.

\section{Basis}

Values are derived from anticipated experimenter needs and available technology. Means shall be provided for determining the elemental composition of gas in flowing streams to a quantitative precision of $\pm 3 \%$ on each chemical species present and with the ability to detect components down to 1 atomic part per million (appm). Channels shall be fully independent to prevent mixing of gas streams.

Desired: Provide means for determining gas composition on 5 channels of flow to and from locations internal to the test volume and 10 channels for locations external to the test volume, with a sensitivity of $0.1 \mathrm{mg} / \mathrm{kg}$ and a precision of $\pm 1 \%$.

\section{Basis}

A further goal is to detect not only component species, but individual isotopes to a resolution better than $0.1 \mathrm{mg} / \mathrm{kg}$. Values are derived from anticipated experimenter needs and available technology.

\subsubsection{Radiological}

Requirement: Radioactivity measurements shall be provided to detect gamma emitters in flowing gas to a precision of $\pm \mathrm{TBDC} i / \mathrm{m}^{3}$, beta emitters to a precision of $\pm T B D C i / \mathrm{m}^{3}$, and alpha emitters to a precision of $\pm T B D C i / \mathbf{m}^{3}$.

\section{Basis}

Values are based on anticipated experimenter needs and technical capabilities.

Desired: Provide on-line spectral analysis of the radioactivity measurements on the gases. 


\section{Basis}

In addition to total beta and gamma measurements, it is important to know the detailed isotopic composition of beta and gamma signals.

The GTL design shall accommodate the withdrawal of witness plates or coupons placed in the experiment to measure plateout of gas components in regions of varying temperature. This shall be done without removal of the test article or major GTL components from the irradiation facility.

Means shall be provided to indicate neutron flux and fast-to-thermal neutron flux ratio in the test volume. This shall include cumulative measurements in at least three locations (near, above, and below core midplane) and an on-line measurement (quasireal-time) in at least one location.

\subsubsection{Data Access}

\section{Requirement: Provide remote, real-time visibility of experiment data.}

\section{Basis}

Means shall be provided for an experimenter using the GTL to have remote, off-site visibility of test data. This does not include command functions, but only passive observation. Care shall be taken to ensure that access to data not directly associated with the GTL is not accessible. Need based on anticipated experimenter requirement and available capability

\subsubsection{Safety and Environment}

Requirement: Comply with federal, state, site-specific and other applicable requirements for safety and environment issues.

\section{Basis}

See the list of potentially applicable regulations in Table 3. Site-specific requirements will be derived from Technical Safety Requirements and Safety Analysis Reports of the host facility.

\subsubsection{Design Lifetime}

\section{Requirement: The required design lifetime of the GTL system shall be 30 years.}

\section{Basis}

The requirement is based on anticipated experimenter needs and typical useful lifetimes of host irradiation facilities. It does not preclude replacement of system components, including the in-core components (if in a reactor), in times shorter than that; but any replacement must be achievable within the limits of a normal facility outage or be accomplished while the facility is operating.

\subsubsection{Codes, Standards, and Regulations}

A listing of applicable codes, standards, and regulations that should be considered in designing the GTL is in Table 2

\subsection{Special Requirements}

Any irradiation facility in which the GTL can be accommodated will have a number of technical constraints that must be met. Several of these are sufficiently general that they become design requirements for the system.

\subsubsection{Experiment Handling}

Means shall be provided for inserting and removing the GTL from its host facility. Removal and installation of loop experiments is accomplished with the irradiation facility shutdown and typically 


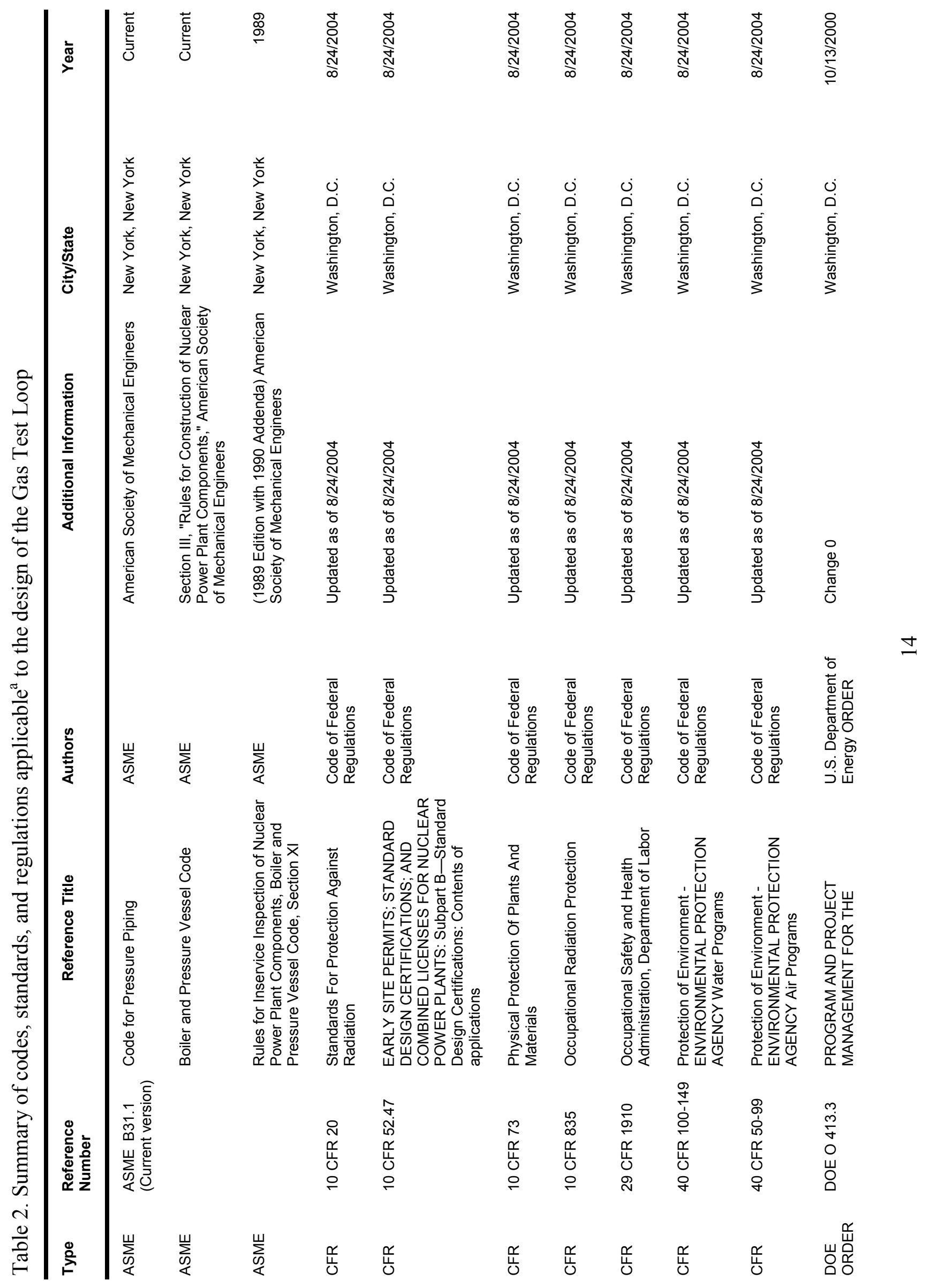




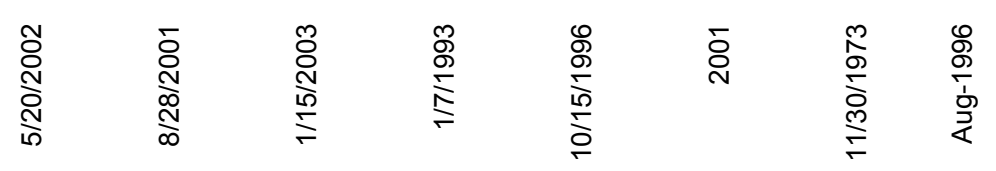
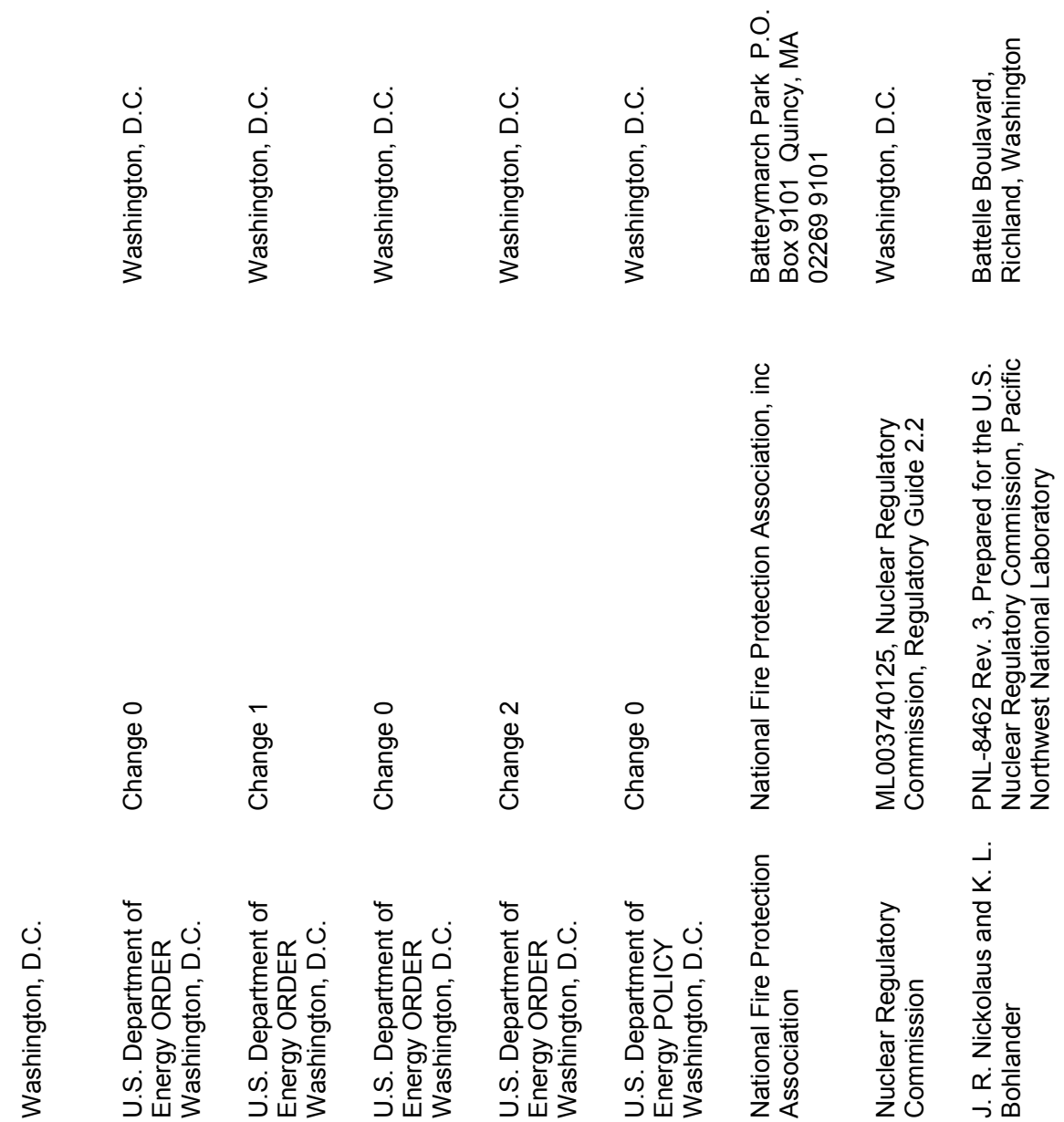

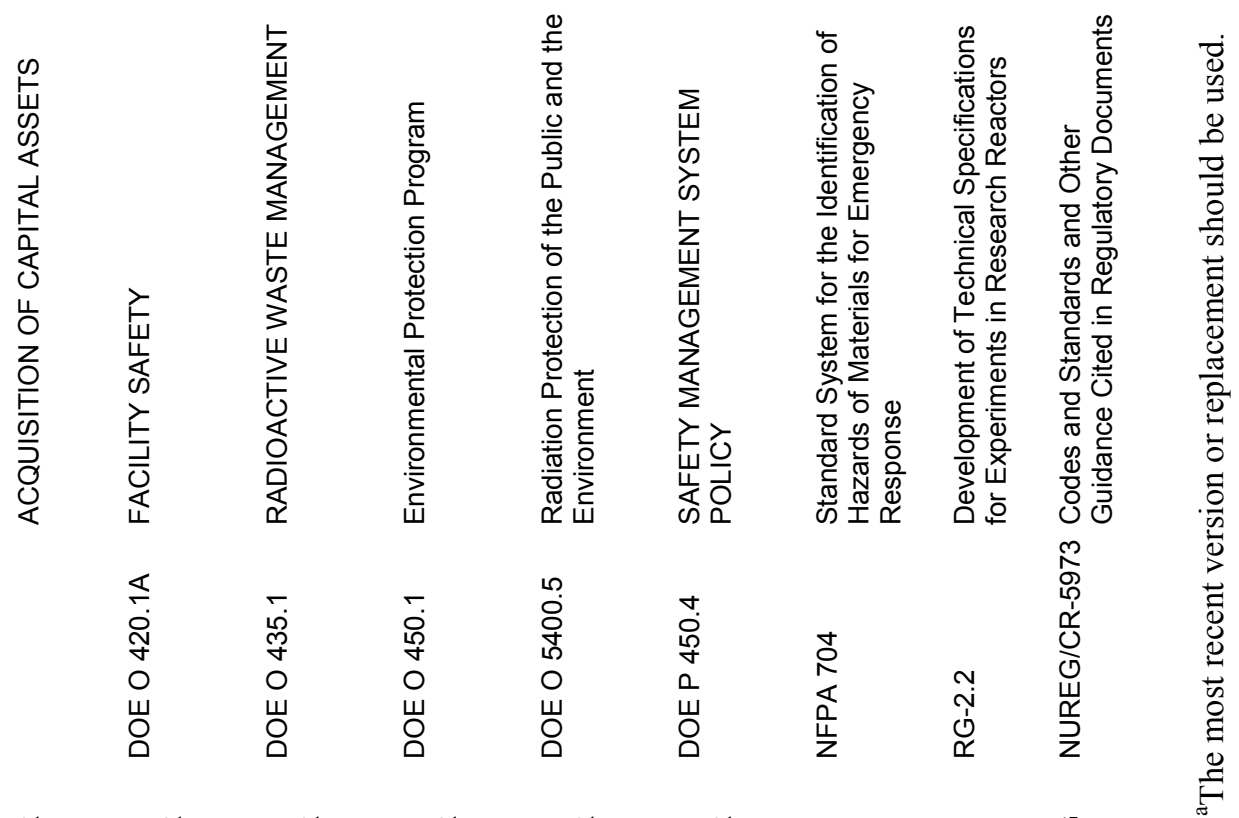

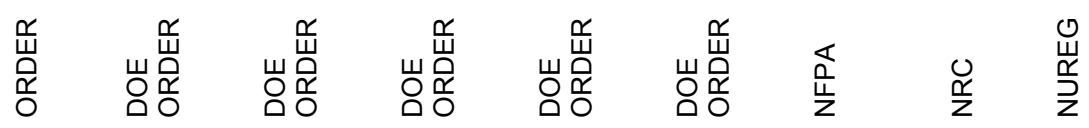


requires that a heavy cask be positioned over the reactor vessel or primary facility enclosure. Each facility has specific heights such loads are allowed to be lifted to preclude catastrophic damage in the event of an inadvertent drop. There may be additional requirements for irradiation facility shut-down during such maneuvers. Design and planning of the GTL shall comply with such requirements at the host facility.

Availability of an adequate cask in which to accomplish the transport required for post-irradiation examination or disposal must be considered in the design. Such a cask may require DOT and/or NRC certification before use.

The design functions of the experiment handling equipment shall ensure that (a) the GTL or any of its components are installed and removed from the irradiation facility without damage to the facility internals, closure plates, or biological shielding, (b) those components are installed, removed and stored in the hot holding facility (e.g., reactor facility canal) without damage to that facility, and (c) to provide radiation shielding for personnel performing handling operations.

\subsubsection{General Design Criteria}

General Design Criteria for most irradiation facilities require that the experiment facilities and their associated out-of-facility SSCs important to safety shall meet applicable requirements of DOE Order 420.1A. Applicable requirements for GTL include

- Nuclear Safety Design Criteria

- Nuclear Criticality Safety

- Natural Phenomena Hazards Mitigation

\subsubsection{Materials Compatibility}

All materials that are exposed to the primary coolant shall be resistant to the corrosive action of the coolant. These are generally limited to aluminum, austenitic stainless steel, and nickel based alloys. The GTL design shall comply with material compatibility requirements for the host irradiation facility.

If the host facility is a nuclear reactor, materials that are incompatible with the reactor fuel element cladding, the reactor primary coolant, canal water, or with the reactor primary coolant system (PCS) structural materials shall be contained to ensure they are not released to the PCS or canal as a result of a Condition 2 (anticipated) or 3 (unlikely) fault.

Incompatible materials, normally used as activation monitors, shall be secured to minimize the likelihood of being lost in the reactor PCS. The following are examples of materials that are chemically incompatible with the PCS: mercury, gold, copper, silver and chlorides. Gold, silver, or other properly reviewed materials may be used as activation monitors, provided they are secured so that the material cannot be lost into the reactor PCS. The preceding materials list is not all-inclusive; there are other materials not listed that are incompatible with the reactor fuel element cladding.

Usage of the following materials shall be shown to be in compliance with the primary experiment safety analyses criterion for the facility.

- Radiologically hazardous activation products

- Radiation sensitive materials

- Highly flammable or toxic materials, per se or as by-products of radiation sensitive materials 
- Reactive Materials, which are defined as any solid or liquid having a reactivity index of 2 in National Fire Protection Association Publication 704 or has a disaster or fire hazard indicating detrimental reactions in water or steam. ${ }^{10}$

\subsubsection{Thermal Hydraulics}

The GTL shall be designed such that conduct of the GTL experiments will not adversely affect decay heat transfer from the canal fuel elements or heat transfer from the PCS.

\subsection{Special Requirements}

\subsubsection{Radiation and Other Hazards}

The GTL shall meet the requirements of DOE 5480.30 with regard to "defense in depth" and "graded approach" in protection from release of radioactive materials.

\subsubsection{ALARA}

The design of the GTL shall incorporate ALARA radiation protection principles, meaning that the radiation dose to operators or others will be as low as reasonably achievable (ALARA), consistent with DOE Order 5480.5.

\subsection{Engineering Design Requirements}

\subsubsection{Mechanical Design Criteria-Code Compliance of Experiment Containment}

The pressure containment boundary shall be designed in accordance with applicable ASME standards or other appropriate standards.

\subsubsection{Chemical and Process}

There are no chemical or process requirements imposed on the GTL to meet its functional performance goals except as may have been previously mentioned in connection with other requirements.

Particular implementations may involve chemicals or processes, the safety of which would dictate special requirements.

\subsubsection{Electrical Power}

There are no inherent electrical power requirements to meet the performance objectives of the GTL except those dictated by accepted codes and standards (see Table 2). Particular implementations may involve electrical power considerations where such requirements would be appropriate.

\subsubsection{Measuring and Test Equipment}

All calibration control activities shall meet the requirements of the established calibration program for the reactor facility. Calibration intervals are established and maintained to ensure acceptable accuracy and reliability of the measurement devices. Calibration requirements for instruments are to be traceable to the National Institute of Standards and Technology (NIST), formerly the National Bureau of Standards (NBS). If this relationship does not exist, the basis of calibration is documented and approved by responsible managers. The calibration requirements are based on the use, accuracy requirement, stability, and amount of usage of the measuring and test equipment (M\&TE).

\subsubsection{Computer Hardware and Software}

Software developed or customized for the GTL shall comply with the requirements of DOE N 203.1 Attachment 1.

\subsubsection{Fire Protection}

Basic requirements for fire protection are in DOE Order 420.1 and DOE 440.1 and their corresponding Contractor Requirements 
Documents (CRD). Guidance for complying with these orders is in DOE G 440.1-5

\subsection{Testing and Maintenance Requirements}

\subsubsection{Testability}

Means shall be provided to allow determination of the GTL's functional readiness, including its ability to provide any required gas mixture, achieve and maintain required temperatures, and measure and record all required data.

\subsubsection{Testing and Inspection Requirements}

Testing and inspection requirements for GTL are those called for by accepted codes and standards (see Table 2) to which the GTL design will conform. Additional requirements may be imposed on a particular implementation by the program it will support.

\subsubsection{TSR-Required Surveillance}

Independent nondestructive examinations shall be performed, as necessary, to confirm the integrity of the outer containment of the GTL. These additional tests and inspections may include helium leak tests, radiography, and ultrasonic or liquid penetrant tests on the GTL.

\subsubsection{Non-TSR Inspections and Testing}

No non-TSR inspection and testing requirements for GTL are inherent to the GTL mission other than those called for by accepted codes and standards (see Table 2) to which the GTL design will conform. Additional requirements may be imposed on a particular implementation by the program it will support.

\subsection{Other Requirements}

\subsubsection{Security and SNM Protection}

All activities on the GTL will comply with 10 CFR 73 and its implementing directives.

\subsubsection{Special Installation Requirements}

Any such requirements will be dictated by the irradiation facility in which the GTL is housed and/or by the users of a particular GTL implementation.

\subsubsection{Common-Mode Failures}

The failure of systems that are common to both the experiment facilities and experiments and to the plant will not cause interactions (from this common use) that result in total consequences exceeding those specified by the facility protection criteria.

\subsubsection{Availability and Reliability}

Experiments placed in the GTL shall be capable of being installed or changed within the limits of a normal irradiation facility outage.

\subsubsection{Quality Assurance}

A Quality Assurance plan shall be developed and observed that conforms to the requirements of DOE Order 414.1B.

\subsubsection{Miscellaneous}

Any such requirements will be dictated by the irradiation facility in which the GTL is housed and/or by the users of a particular GTL implementation. 


\section{REFERENCES}

1. Idaho National Engineering and Environmental Laboratory, June 28, 2004, "Justification of Mission Need for the Gas Test Loop, INEEL/EXT-0402018 .

2. National Aeronautics and Space Administration, February 2004, The Vision for Space Exploration, http://www.nasa.gov/pdf/55584main_vi sion space exploration-hi-res.pdf.

3. U.S. DOE Nuclear Energy Research Advisory Committee and the Generation IV International Forum, December 2002, A Technology Roadmap for Generation IV Nuclear Energy Systems, GIF-002-00.

4. G. S. Chang, April 19, 2004, Subject: Neutronics Scoping Analysis of the Proposed Fuel Booster Assemblies, Interoffice memorandum to H. D. Gougar, GSCGTL-01-2004

5. U.S. DOE Nuclear Energy Research Advisory Committee and the Generation IV International Forum, December 2002, A Technology Roadmap for Generation IV Nuclear Energy Systems, GIF-002-00, p.49.
6. Idaho National Engineering and Environmental Laboratory, June 28, 2004, "Justification of Mission Need for the Gas Test Loop, INEEL/EXT-0402018, p. 10.

7. U.S. DOE Nuclear Energy Research Advisory Committee and the Generation IV International Forum, December 2002, A Technology Roadmap for Generation IV Nuclear Energy Systems, GIF-002-00, p.43.

8. G. R. Longhurst, B. G. Schnitzler, B. T. Parks, "Multi-Megawatt Power System Trade Study," Space Technology and Applications International ForumSTAIF 2002, Albuquerque, NM, 3-6 February 2002, AIP Conference Proceedings Vol. 608.

9. U.S. DOE Nuclear Energy Research Advisory Committee and the Generation IV International Forum, December 2002, A Technology Roadmap for Generation IV Nuclear Energy Systems, GIF-002-00, p.67.

10. R. J Lewis, Jr., 1990, Sax's Dangerous Properties of Industrial Materials, Eighth Edition (later editions may be used), Van Nostrand Reinhold, New York, New York, circa 1990. 



\section{APPENDIX A GENERATION IV REACTOR CONCEPTS}

Information on the Generation IV reactor concepts comes from A Technology Roadmap for Generation IV Nuclear Energy Systems, December 2002, GIF-002-00, U.S. DOE Nuclear Energy Research Advisory Committee and the Generation IV International Forum.

\section{A.1 Gas-Cooled Fast Reactor}

The GFR system features a fast-spectrum helium-cooled reactor and closed fuel cycle. The GFR uses a direct-cycle helium turbine for electricity and can use process heat for thermochemical production of hydrogen. Through the combination of a fast neutron spectrum and full recycle of actinides, GFR minimize the production of long-lived radioactive waste isotopes. The GFR's fast spectrum also makes it possible to utilize available fissile and fertile materials (including depleted uranium from enrichment plants) two orders of magnitude more efficiently than thermal spectrum gas reactors with once through fuel cycles. The GFR reference assumes an integrated, on-site spent fuel treatment and fabrication plant.

A summary of design parameters for the GFR system is given in Table A-1.

Table A-1. Design parameters for the Gas-Cooled Fast Reactor system.

\begin{tabular}{|l|l|}
\hline \multicolumn{1}{|c|}{ Reactor Parameters } & \multicolumn{1}{c|}{ Reference Value } \\
\hline Reactor Power & $600 \mathrm{MWth}$ \\
Net plant Efficiency (direct helium cycle) & $48 \%$ \\
Coolant inlet/outlet temperature & $490{ }^{\circ} \mathrm{C} / 850{ }^{\circ} \mathrm{C}$ \\
Pressure & $90 \mathrm{bar}(9 \mathrm{MPa})$ \\
Average power density & $100 \mathrm{MWTH} / \mathrm{m}^{3}$ \\
Reference fuel compound & $\mathrm{UPu} / \mathrm{SiC}(70 / 30 \%)$ with about \\
& $20 \% \mathrm{Pu}$ content \\
Volume fraction, Fuel/Gas/SiC & $50 / 40 / 10 \%$ \\
Conversion ratio & Self-sufficient \\
Burnup, Damage & $5 \% \mathrm{FIMA}$ or 250 \\
Fuel center line temperature (operating) & GWD/MTHM; 60 dpa (up to \\
\end{tabular}

Fuel: 
A composite ceramic-ceramic fuel (cercer) with closely packed, coated (U, Pu) $\mathrm{C}$ kernels or fibers is the best option for fuel development. Alternative fuel options include fuel particles with large $(\mathrm{U}, \mathrm{Pu}) \mathrm{C}$ kernels and thin coatings or ceramic-clad solid-solution metal (cermet) fuels. The need for high densities of heavy nuclei in the fuel leads to actinide-carbide as the reference fuel and actinide-nitrides with $99.9 \%$ enriched nitrogen as the backup.

Other:

The structural materials, in-core and out-of-core, pose a great challenge in designing of the reactor as it will have to withstand high fast-neutron fluence and temperature, up to $1600{ }^{\circ} \mathrm{C}$ in accident situations.

R\&D activities need to identify the materials that offer the best compromise regarding:

- Ability to fabricate and weld

- Chemical and neutronic compatibility with the core environment.

\section{A.2 Lead-Cooled Fast Reactor System}

Lead cooled fast reactor (LFR) systems are $\mathrm{Pb}$ or $\mathrm{Pb}$-Bi alloy cooled reactors. They feature a fast neutron spectrum and closed fuel cycle. The LFR system is strong in sustainability because a closed fuel cycle is used, and in proliferation resistance and physical protection because it employs a long core-life. The reactor is cooled by natural convection with outlet coolant temperature of $550{ }^{\circ} \mathrm{C}$, possibly ranging up to $800{ }^{\circ} \mathrm{C}$. A summary of design parameters for the LFR system is given in Table A-2.

Table A-2. Design parameters for the Lead-Cooled Fast Reactor system.

\begin{tabular}{|l|l|}
\hline \multicolumn{1}{|c|}{ Reactor Parameters } & \multicolumn{1}{c|}{ Reference Value } \\
\hline Reactor Power & $125-3600 \mathrm{MWth}$ \\
Max Fuel temperature (Normal Operation) & $710{ }^{\circ} \mathrm{C}$ \\
Max Cladding temperature (Accident condition) & $725{ }^{\circ} \mathrm{C}$ \\
Coolant & $\mathrm{Pb}$ or Pb-Bi \\
Coolant inlet/max outlet temperature & $550-800{ }^{\circ} \mathrm{C}$ \\
Pressure & 1 atm $(101.3 \mathrm{kPa})$ \\
Average burnup & $100-150 \mathrm{GWD} / \mathrm{MTHM}$ \\
Power Density & $140-254 \mathrm{~kW} / 1$ \\
Reference fuel compound & Metal alloy or mixed nitride \\
Cladding & Ferritic or ceramic coatings \\
Conversion ratio & 1 \\
\hline
\end{tabular}

Fuel: 
The nearer-term options plan to use a nitride or metal alloy fuel. Metal alloy fuel pin performance at $550{ }^{\circ} \mathrm{C}$ and U/TRU/Zr metal alloy recycle and remote fabrication technologies are already substantially developed in Na-cooled systems. Nitride fuel development includes fuel/clad interaction, compatibility and performance. Mixed nitride fuel is also possible for the $550{ }^{\circ} \mathrm{C}$ options; however, it will be required for the high temperature option.

Other:

Strategies and means for control of ${ }^{210} \mathrm{Po}$, an activation product of $\mathrm{Bi}$, are needed for the $\mathrm{Pb}-\mathrm{Bi}$ option. Research and development of composites, coatings, ceramics, and hightemperature alloy for fuel cladding and reactor structure are needed. A long-term goal is to have coolant outlet temperature up to $800{ }^{\circ} \mathrm{C}$.

\section{A.3 Molten-Salt Reactor System}

The molten-salt reactor (MSR) produces fission power in a circulating molten salt fuel mixture. MSRs are fueled with uranium or plutonium fluorides dissolved in a mixture of molten fluorides, with $\mathrm{Na}$ and $\mathrm{Zr}$ fluorides in a closed fuel cycle. The MSR system is strong in sustainability because of its closed fuel cycle and excellent performance in waste burn-down. It is rated good in safety and in proliferation resistance and physical protection. However, the MSR system features an epithermal to thermal neutron spectrum.

\section{A.4 Sodium-Cooled Fast Reactor System}

The sodium-cooled fast reactor system (SFR) features a fast-spectrum reactor and a closed fuel recycle system. The SFR size varies from a few hundred MWe to large monolithic reactors of 1500-1700 MWe. The sodium outlet temperature is typically near $550{ }^{\circ} \mathrm{C}$. There are two types of concepts: pool layout, where all primary system components are housed in a single vessel, similar to EBR-II; or in a compact layout similar to one of the Japanese reactor designs. The primary system operates at essentially atmospheric pressure. SFRs have been built and operated in France, Germany, Japan, Russia, United Kingdom and United State of America. There is an extensive technology base in nuclear safety that establishes the passive safety characteristic of the SFR. It has been proven that the reactors can survive fuel damage in the case of anticipated transient without scram events. A summary of design parameters for the SFR system is given in Table A-3.

Table A-3. Design parameters for the Sodium-Cooled Fast Reactor system.

\begin{tabular}{|l|l|}
\hline \multicolumn{1}{|c|}{ Reactor Parameters } & \multicolumn{1}{c|}{ Reference Value } \\
\hline Reactor Power & $100^{\prime} \mathrm{s}-1700 \mathrm{MWe}$ \\
Coolant & Sodium \\
Coolant temperature & $530-550^{\circ} \mathrm{C}$ \\
Pressure & $1 \mathrm{~atm}(101.3 \mathrm{kPa})$ \\
Average burnup & $150-200 \mathrm{GWD} / \mathrm{MTHM}$ \\
Power Density & $350 \mathrm{~kW} / \mathrm{L}$ \\
\hline
\end{tabular}




\begin{tabular}{|l|l|}
\hline Reference fuel compound & Metal alloy or Mixed oxide \\
Conversion ratio & $0.5-1.3$ \\
\hline
\end{tabular}

Fuels:

Two fuel options exist for the SFR, MOX and mixed uranium-plutonium-zirconium metal alloy. Both are highly developed as a result of many years of experience in several nations. Burnup in both types of fuel has been experimentally demonstrated to be in the range of 150-200 GWd/MT. The database for MOX fuel is considerably more extensive than that for metal fuel.

\section{A.5 Supercritical-Water-Cooled Reactor System}

The Supercritical Water Reactor (SCWR) is based on the principle that for pressures above the critical pressure in water there is no phase change of the fluid at any temperature. This offers the potential for higher thermal efficiency $(\sim 44 \%)$ than light water reactors (LWR) ( 35\%), lower primary coolant mass, resistance to boiling crisis events, and greater simplicity. The design reflects work in Japan over the last two decades and considerable experience in the fossil power industry. High-pressure coolant $(25 \mathrm{MPa})$ enters the vessel at $280^{\circ} \mathrm{C}$. It is heated to about $510^{\circ} \mathrm{C}$ and delivered to a power conversion cycle, which blends LWR and supercritical fossil plant technology. It can be designed to operate on either a fast or a thermal neutron spectrum. Table A-4 lists some of the key design parameters for a thermal spectrum SCWR design.

Table A-4. Design parameters for a thermal-spectrum Supercritical Water Reactor system.

\begin{tabular}{|l|l|}
\hline \multicolumn{1}{|c|}{ Reactor Parameters } & \multicolumn{1}{c|}{ Reference Value } \\
\hline Reactor power & $1,700 \mathrm{MWe}$ \\
\hline Coolant inlet/outlet temperature & $280^{\circ} \mathrm{C} / 510^{\circ} \mathrm{C}$ \\
\hline Coolant pressure & $25 \mathrm{MPa}$ \\
\hline Average power density & $\sim 100 \mathrm{MWth} / \mathrm{m}^{3}$ \\
\hline Reference fuel & $\begin{array}{l}\mathrm{UO}_{2} \text { with austenitic or ferritic-martensitic } \\
\text { stainless steel, or Ni-alloy cladding }\end{array}$ \\
\hline Fuel structural materials & $\begin{array}{l}\text { Advanced high-strength metal alloys are } \\
\text { needed }\end{array}$ \\
\hline Burnup / Damage & $\sim 45 \mathrm{GWD} / \mathrm{MTHM} ; 10-30$ dpa \\
\hline
\end{tabular}




\section{A.6 Very-High-Temperature Reactor System}

The Generation IV roadmap identified the VHTR, based on the current state of technology, potential for successful development of near term and future advanced technologies. The VHTR technology base has primarily evolved from commercial gas-cooled reactors built and operated in Western Europe and the United States and two research reactors currently operating in Japan and China. The VHTR is a next step in evolutionary development of high-temperature gascooled reactor which can be a direct or indirect cycle. The reference VHTR is $600 \mathrm{MWth}$ and can produced hydrogen from high temperature steam using thermo-chemical iodine-sulfur (I-S) process. The VHTR can also generate electricity with over 50\% efficiency as coolant outlet temperature is expected to be $1000{ }^{\circ} \mathrm{C}$. The VHTR is graphite-moderated, helium-cooled reactor with a thermal neutron spectrum. A summary of design parameters for the VHTR system is given in Table A-5.

Table A-5. Summary of design parameters for the Very-High-Temperature Reactor system.

\begin{tabular}{|l|l|}
\hline \multicolumn{1}{|c|}{ Reactor Parameters } & \multicolumn{1}{c|}{ Reference Value } \\
\hline Reactor Power & $600 \mathrm{MWTH}$ \\
Max Fuel temperature (Normal Operation) & $1200{ }^{\circ} \mathrm{C}$ \\
Max Fuel temperature (Accident Condition) & $1800{ }^{\circ} \mathrm{C}$ \\
Max Cladding temperature (Accident condition) & $\mathrm{TBD}{ }^{\circ} \mathrm{C}$ \\
Coolant & Helium \\
Coolant temperature & $640-1000{ }^{\circ} \mathrm{C}$ \\
Pressure & Process dependent \\
Average burnup & $150-200 \mathrm{GWD} / \mathrm{MTHM}$ \\
Power Density & $6-10 \mathrm{~kW} / 1$ \\
Reference fuel compound & $\mathrm{ZrC}-\mathrm{coated}$ particles in blocks, pins \\
Conversion ratio & or pebbles \\
Plant Efficiency & $0.5-1.3$ \\
\hline
\end{tabular}

Fuels:

The increase in the coolant outlet temperature of the VHTR will require an increase in the fuel temperature. This will significantly reduce the safety margin, compared to current light water reactors, in core heat-up events. Fuel particles coated with $\mathrm{SiC}$ are used in HTGR at fuel temperatures of approximately $1200{ }^{\circ} \mathrm{C}$. New material, such as zirconium-carbide, has been suggested for fuel temperatures above $1200{ }^{\circ} \mathrm{C}$. The Next-Generation Nuclear Plant (NGNP) high level function and requirements document favors TRISO-coated fuel particles, each containing a kernel $(0.5 \mathrm{~mm})$ of uranium oxycarbide $(\mathrm{UCO})$ or uranium dioxide enclosed in a 
coating shell. The fuel particles may be agglomerated into cylindrical compacts or into spherical pebbles (up to $6 \mathrm{~cm}$ in diameter).

\section{Other:}

Since core outlet temperature is expected to be greater than $1000{ }^{\circ} \mathrm{C}$, a significant amount of materials research work will be needed for the core internals and pressure vessel, which may have a nominal operating temperature of up to $650{ }^{\circ} \mathrm{C}$. In the case of perturbed conditions, potentially higher temperature may exist for tens of hours.

In the original HTGR design, some components of the reactor, such as the side reflector, core blocks, and core support, were made from H-327/H-451graphite, which is no longer available. A number of replacement graphites may be available; however, irradiation properties and test data are needed.

\section{A.7 Summary Data}

A comparative summary of design features of the GEN IV reactors is provided in Tables A-6 and A-6.

Table A-6. Fuel and structural material options for the various GEN IV reactors.

\begin{tabular}{|c|c|c|c|c|c|c|c|c|c|c|c|c|}
\hline \multirow[b]{2}{*}{ System } & \multicolumn{5}{|c|}{ Fuel Materials } & \multicolumn{7}{|c|}{ Structural Materials } \\
\hline & $\frac{d}{d}$ & $\begin{array}{l}\bar{\pi} \\
\sum \\
\Sigma\end{array}$ & $\begin{array}{l}\frac{0}{0} \\
\frac{0}{z} \\
\mathbf{z}\end{array}$ & $\begin{array}{l}\frac{0}{0} \\
\frac{0}{0} \\
\frac{1}{\pi} \\
ن\end{array}$ & $\begin{array}{l}\text { 음 } \\
\text { 을 } \\
\text { 흔 }\end{array}$ & 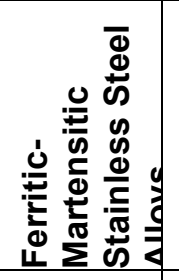 & 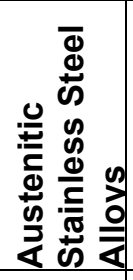 & 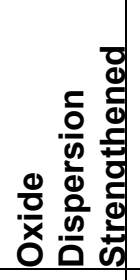 & 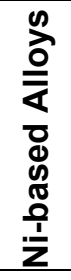 & $\begin{array}{l}\stackrel{0}{ \pm} \\
\frac{2}{0} \\
\frac{0}{0} \\
\frac{0}{0}\end{array}$ & 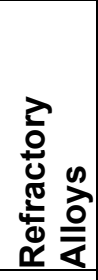 & 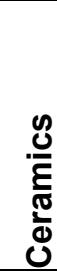 \\
\hline GFR & & & $S$ & $\mathrm{P}$ & & $P$ & $P$ & $P$ & $P$ & & $P$ & $\mathrm{P}$ \\
\hline MSR & & & & & $\mathrm{P}$ & & & & $P$ & $P$ & $S$ & $S$ \\
\hline SFR & $P$ & $P$ & & & & $P$ & $P$ & $P$ & & & & \\
\hline LFR & & $S$ & $P$ & & & $P$ & $P$ & $S$ & & & $S$ & $S$ \\
\hline SCWR-Thermal & $P$ & & & & & $P$ & $P$ & S & $S$ & & & \\
\hline SCWR-Fast & $P$ & S & & & & $P$ & $P$ & S & $S$ & & & \\
\hline VHTR & $P$ & & & & & $S$ & & & $P$ & $\mathrm{P}$ & S & $\mathrm{P}$ \\
\hline $\begin{array}{l}\text { P: Primary Option } \\
\text { S: Secondary Option }\end{array}$ & & & & & & & & & & & & \\
\hline
\end{tabular}




\begin{tabular}{|c|c|c|c|c|c|c|c|c|}
\hline 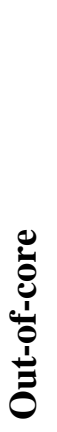 & 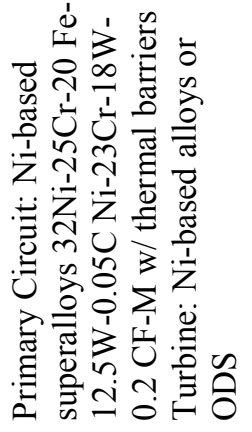 & 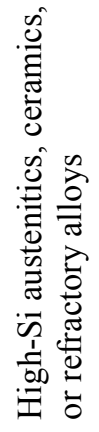 & 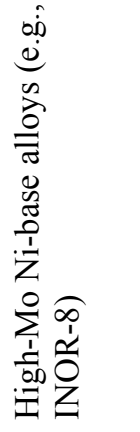 & 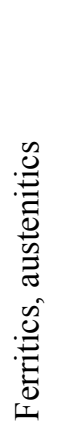 & 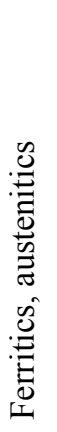 & $\sum_{1}$ & $\sum_{1}$ & 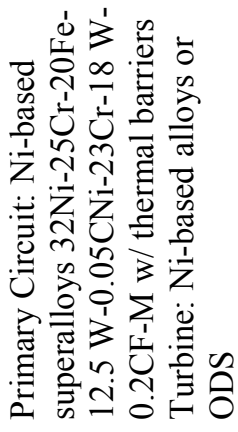 \\
\hline 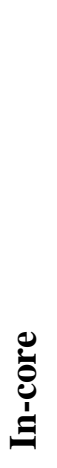 & 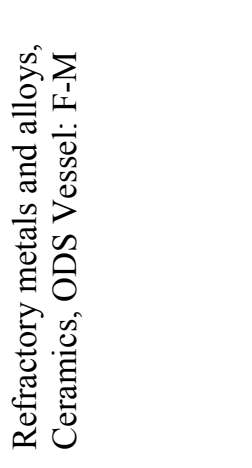 & & 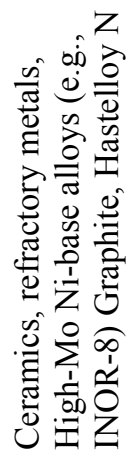 & 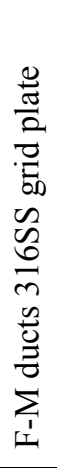 & 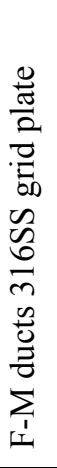 & 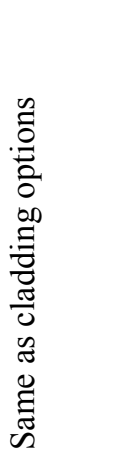 & 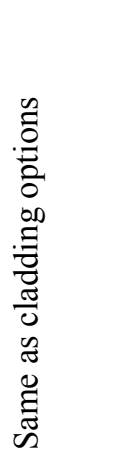 & 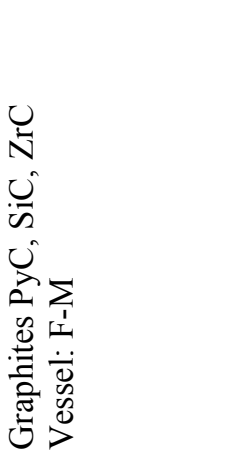 \\
\hline 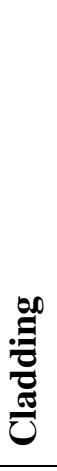 & 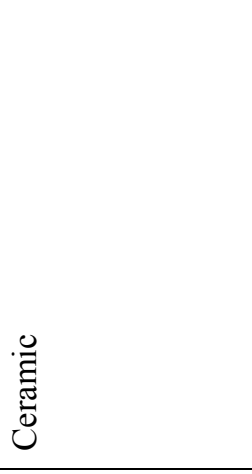 & 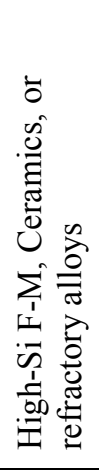 & 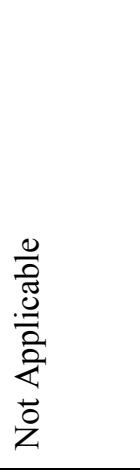 & 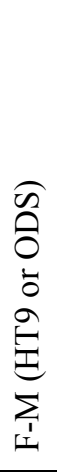 & $\tilde{0}$ & 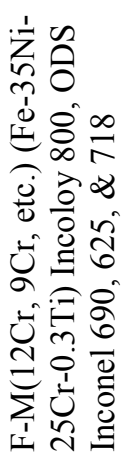 & 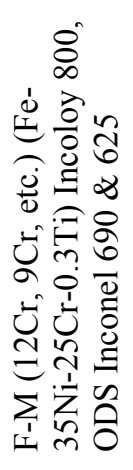 & 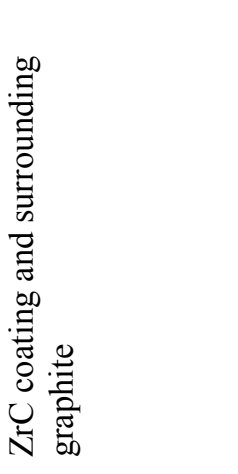 \\
\hline$\underset{\Xi}{\Phi}$ & 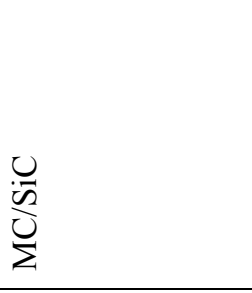 & $Z_{\Sigma}^{Z}$ & $\begin{array}{l}\text { 司 } \\
\stackrel{n}{n}\end{array}$ & 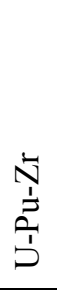 & 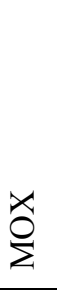 & న̊ & 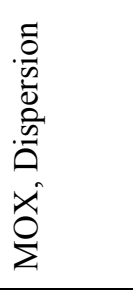 & 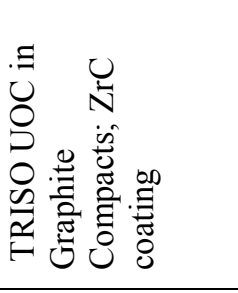 \\
\hline 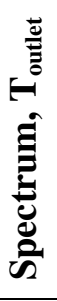 & 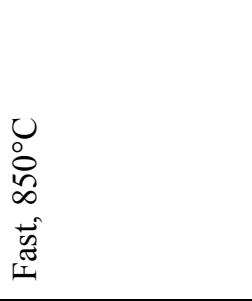 & 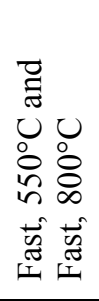 & 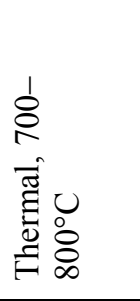 & 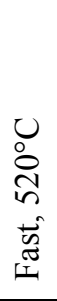 & 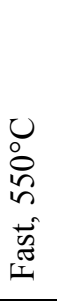 & 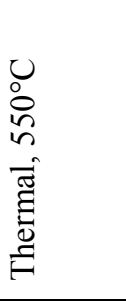 & 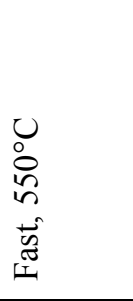 & 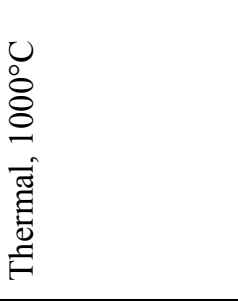 \\
\hline$\frac{5}{0}$ & $\frac{\sqrt{1}}{\mathbb{U}}$ & 恖 & $\frac{\tilde{v}}{\Sigma}$ & 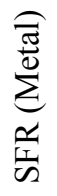 & 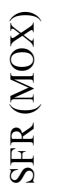 & 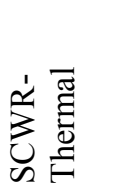 & 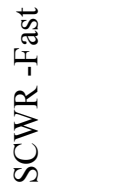 & 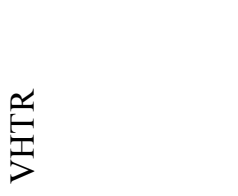 \\
\hline
\end{tabular}




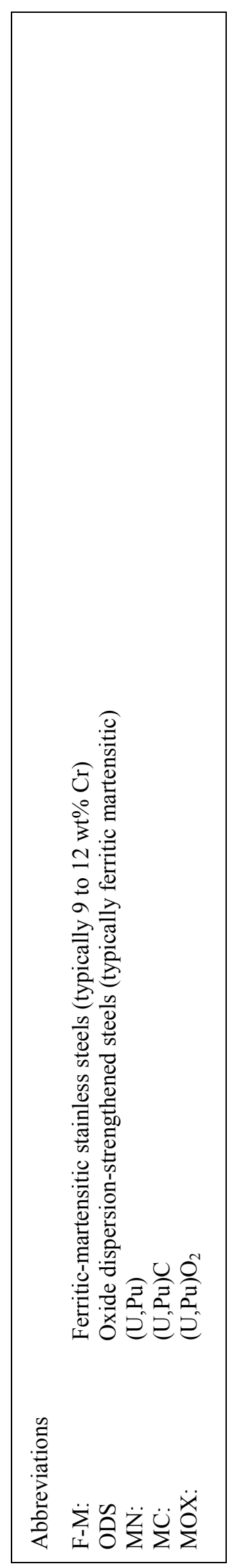

